

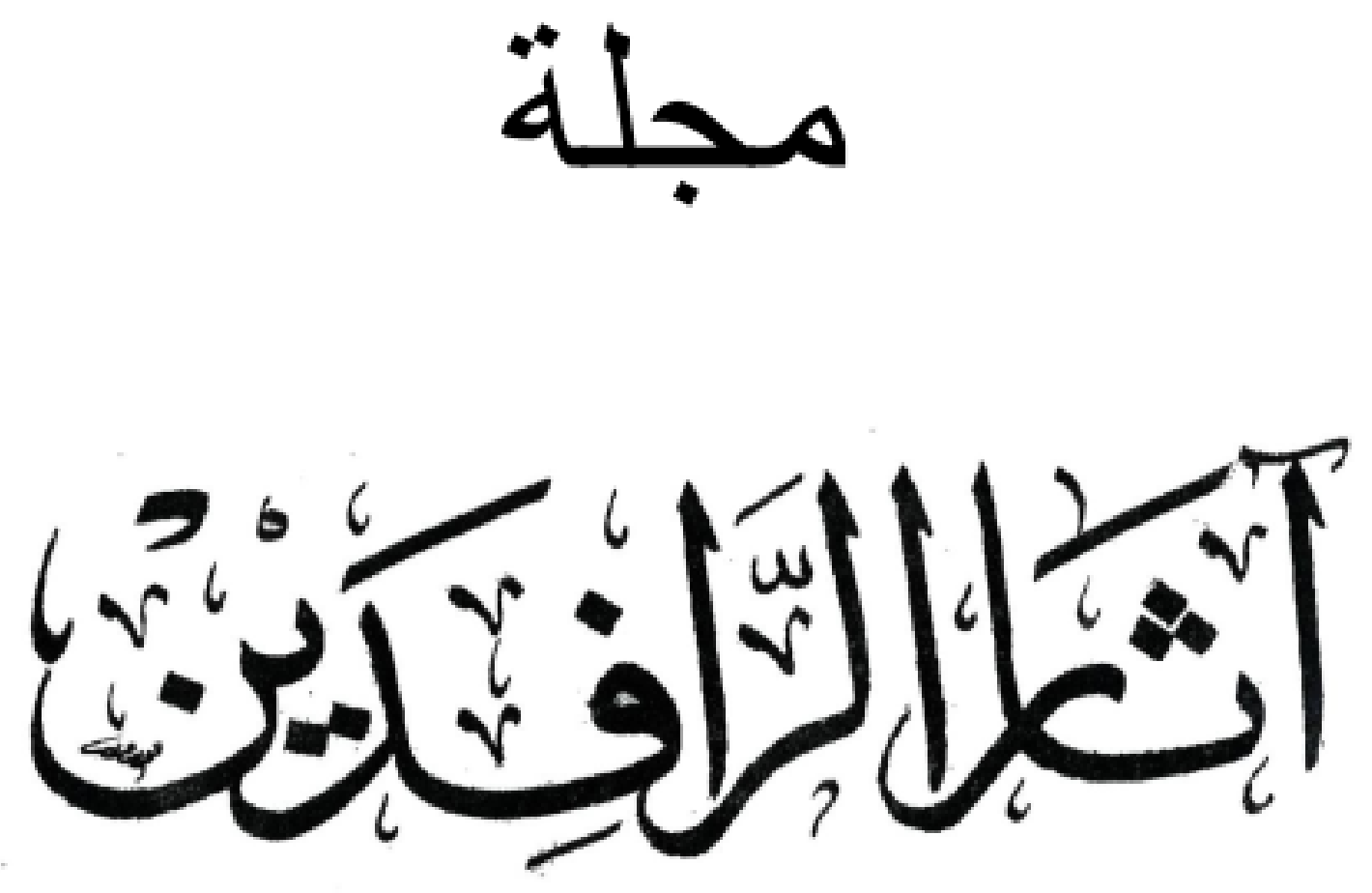

هبلة علمية هحكمة تبحث في آثار العراق و الشرق الأدنى القديم تصدر عن كلية الآثار في جاهعة الموصل

E-Mail: uom.atharalrafedain@ gmail.com البريد الاكتروني

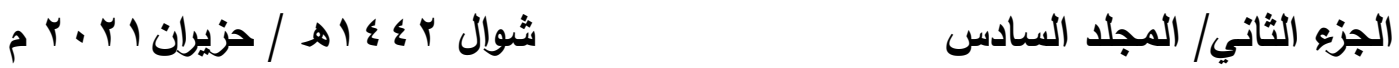

$$
\begin{aligned}
& \text { رقم الايداع في دار الكتب والوثائق بيغداد }
\end{aligned}
$$

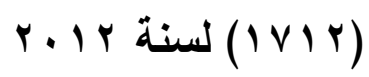





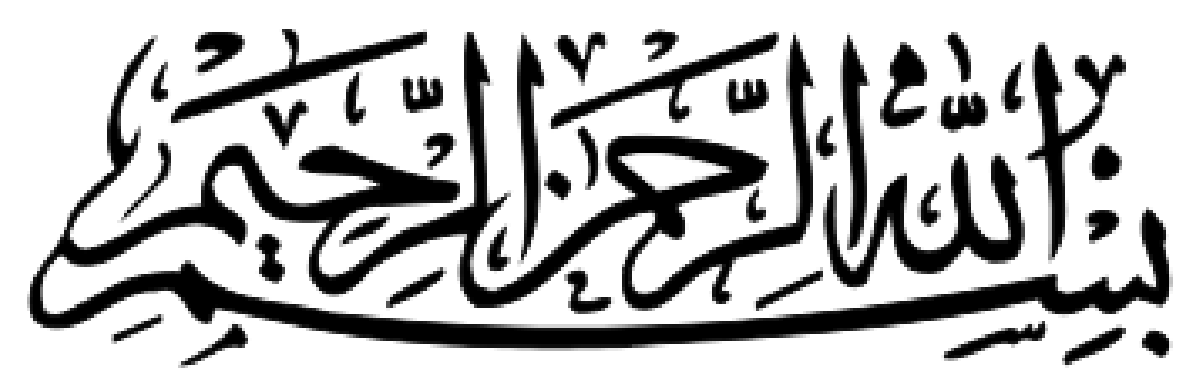





\section{هيأة التمرير}

أ. خالد سالم اسماءيل

رئيس التمرير

أ.م. هسنين حيدر عبد الواحد

الاعضاء

أ.د. اليزابيث ستون

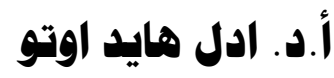

أ.د. والتز سلابيركر

أ.د. نيكولو هاركيتي

أ.د. هديب حياوي عبد الكريم

أ.د. جواد هطر الموسوي

أ.د. رفاه جاسم حمادي

أ.د. عادل هاشم علي

أ.م.د. ياسمين عبد الكريم هممد علي

أ.م.د. فيسان هوفق رشيد

أ.م.د. هاني عبد الغني عبد الله 


$$
\begin{aligned}
& \text { هقوم اللغة العربية } \\
& \text { أ.م.د. همن يميى هصمد }
\end{aligned}
$$

\author{
هقوم اللغة الانكيلية

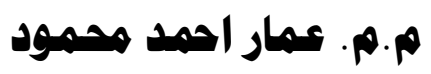 \\ قسم الترجمة / كلية الآداب / جامعة الموصل
}

$$
\text { د. تصميم الغلاف }
$$




\section{قواعد النشر في مجلة آثار الرافدين}

$$
\begin{aligned}
& \text { 1- تقبل المجلة البحوث العلمية التي تقع في تخصصات: } \\
& \text { • علم الاثار بفرعيه القديم والإسلامي . } \\
& \text { • • اللغات القديمة بلهجاتها و الدراسات الدقارنة. } \\
& \text { • الكتابات المسمارية و الخطوط القديمة . }
\end{aligned}
$$

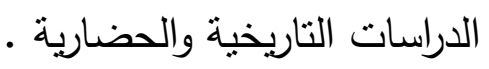

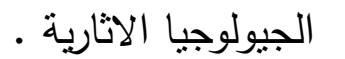

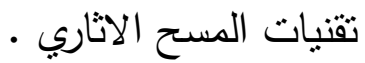

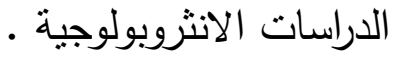

$$
\begin{aligned}
& \text { • الصيانة والتزميم الصنان }
\end{aligned}
$$

r- تقدم البحوث الى المجلة باللغتين العببية أو الانكليزية .

r-يطبع البحث على ورق (A4)، وبنظام (2010 - word)، وبمسافات مزدوجة بين الاسطر ، وبخط Simplified Arabic للغة العربية، و Times New Roman للغة

$$
\text { الانكليزية، ويسلم على قرص ليزري (CD) ، وبنسختين ورقيتين. }
$$

ع- يطبع عنوان البحث في وسط الصفحة يليه اسم الباحث ودرجته العلمية ومكان عمله

$$
\text { كاملاً والبريد الالكتروني (e-mail) }
$$

ه- يجب ان يحتوي البحث ملخصا باللغتين العربية والانكليزية على ان لا تزيد عن (. ( ) كلمة.

4- يحتوي ملخص البحث بالإنكليزية على عنوان البحث واسم الباحث ودرجته العلمية ومكان عمله كاملاً والبريد الالكتروني له. V- تضمين البحث كلمات مفتاحية تتعلق بعنوان البحث ومضمونه. ^- ان لا يكون البحث قد تم نشره سابقا أو كان مقدما لنيل درجة علمية أو مستلاً من ملكية

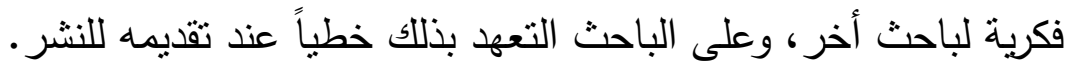
9- يلتزم الباحث باتباع الاسس العلمية السليمة في بحثه. • 1- يلزم الباحث بتعديل فقرات بحثه ليتناسب مع مقترحات الخبراء واسلوب النشر في 
11- لا تتجاوز عدد صفحات البحث عن (ro)، صفحة وفي حال تجاوز العدد المطلوب يتكفل الباحث بدفع مبلغاً اضافياً عن كل صفحة اضافية.

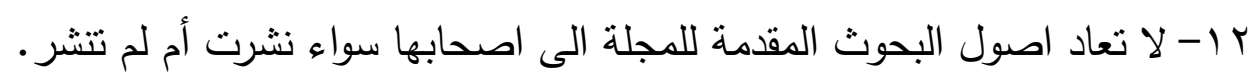
با ا-ترقم الجداول والاشكال على التوالي وبحسب ورودها في البحث، وتزود بعناوين، وتقدم بأوراق منفصلة وتقام المخططات بالحبر الاسود والصور تكون عالية الدقة. ع ا-تكتب ارقام الهوامش بين قوسين وترد متسلسلة في نهاية البحث.

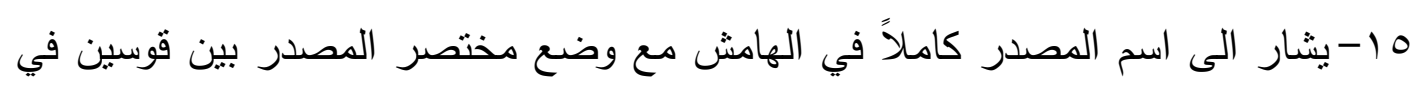
نهاية الهامش.

17 - يتحمل الباحث تصحيح ما يرد في بحثه من اخطاء لغوية وطباعية. V V Vعمل المجلة وفق التمويل الذاتي، ولذلك يتحمل الباحث اجور النشر البالغة

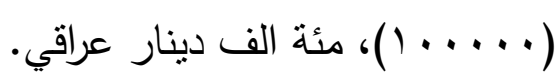

11 ا- يزود كل باحث بمستل من بحثه، أما نسخة المجلة كاملة فتطلب من سكرتارية المجلة

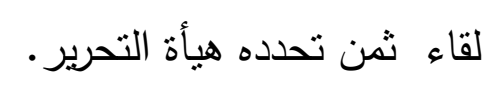
9 1 - ترسل البحوث على البريد الالكتروني للمجلة: uom.atharalrafedain@gmail.com 
ثبت المحتويات

\begin{tabular}{|c|c|c|}
\hline العنوان & اسم الباحث & الصفحة \\
\hline توطئة & أ. خالد سالم اسماعيل & 1 \\
\hline النخيل في الفن العراقي القديم & أ.د. واثق اسماعيل الصالحي & $\Delta r-r$ \\
\hline أضواء على المراسيم الملكية من العصر البابلي القديم & أ. خالد سالم اسماعيل عبد الغني & $q \leq-\Lambda r$ \\
\hline من مدن القوافل ومحطات الطرق على مر العصور التأريخية القديمة & أ.د. عامر عبد الله الجميلي & $1 r r-90$ \\
\hline شجرة الطرفاء في ضوء الكتابات المسمارية & 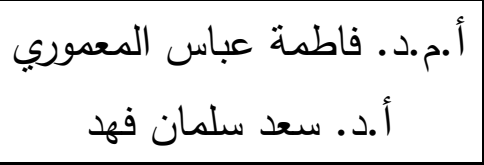 & תrו-. \\
\hline 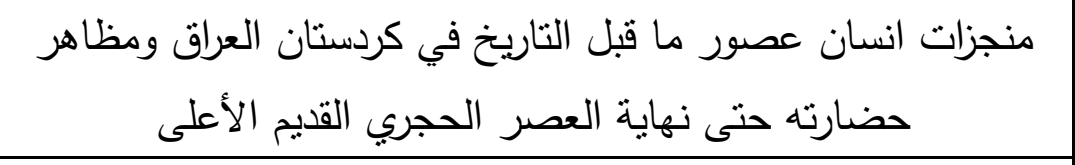 & أ.م.د. نعمان جمعة ابراهيم & $|\wedge 7-17|$ \\
\hline 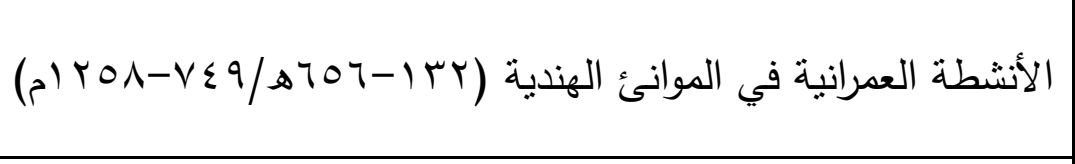 & أ.د. م. قاسفم عمر علاوي ياسين ابراهيم & $r \cdot \varepsilon-1 \wedge V$ \\
\hline ل المظاهر النظافة في المجتمع الحثي & أ.م.د. هاني عبدالغني عبداله & YrI-Y.0 \\
\hline الصيغة المزيدة بالتاء (Gt) في اللغة الأكدية دراسة صرفية دلالية & د. مصطفى محسن محمد & YO.-YYT \\
\hline 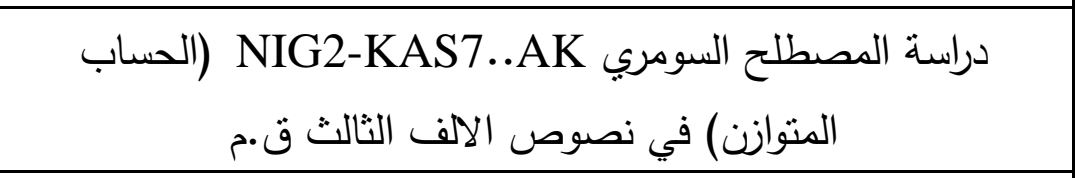 & م.م. عبد الدُكرِمِ محمود العزّي & rтq-rol \\
\hline تطور صناعة المنجل في العراق القديم خلال العصر الحجري الوسيط & م•م• حسن مهدي حمودي & $Y \wedge V-Y V I$ \\
\hline
\end{tabular}





\section{الصيغة المزيدة بالتاء (Gt) في اللغة الأكدية دراسة صرفية دلالية مقارنة مع اللغتين العبرية والعربية د. مصطقى محسن محمد}

كلية الآثار/ قسم اللغات العراقية القديمة مدمئ

\section{mustafamehsen2@gmail.com}

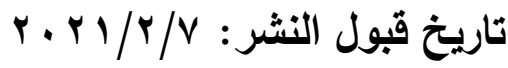

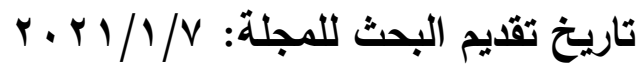

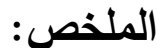

تزخر اللغة الأكدية بالعديد من الصيغ المزيدة بما فيها صيغة (Gt) ويتمض هذان

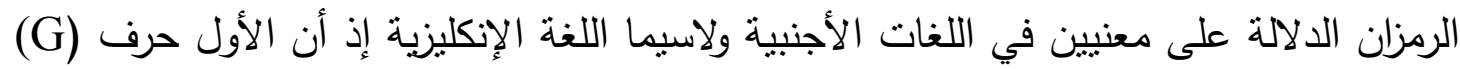

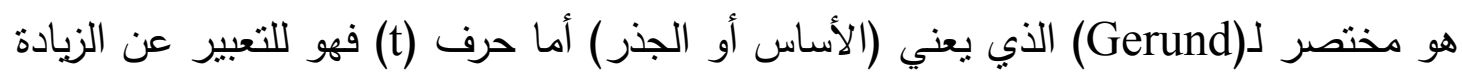
الحاصلة على وزن الصيغة الأساس، والصيغة (Gt) هي نتاج طبيعي ولدت من رحم الحاجة الحسات

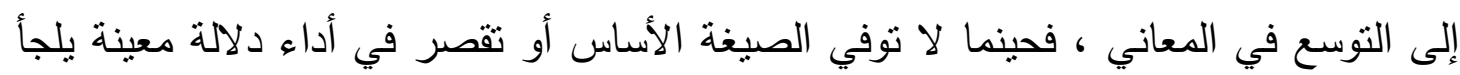

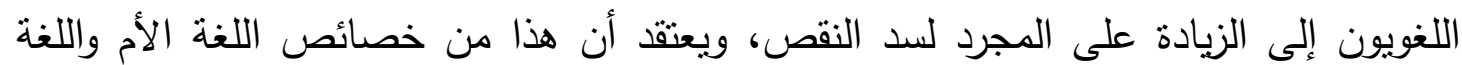

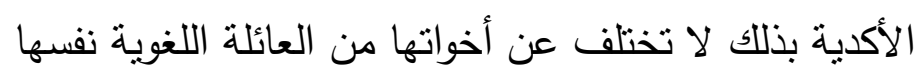

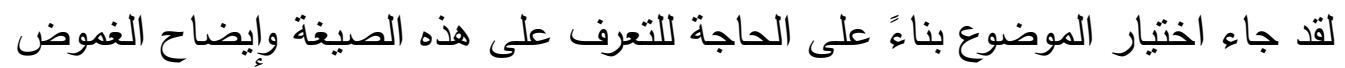

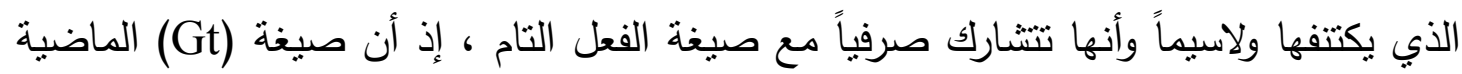

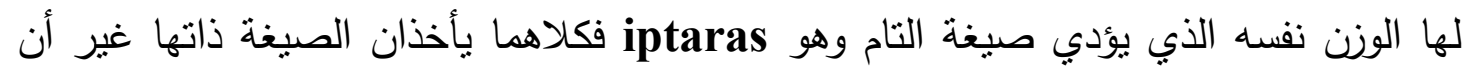
القصد مختلف فصيغة التام تعبر عن زمن معين ، في حين أن صيغة (Gt) لها وظائف أخرى تختلف عن صيغ التام ،ومن هنا برزت الحاجة إلى توضيح هذه الصيغة والخوض في مضانها ، فالباحث في اللغات القديمة وقارئ المسماريات لا يمكنه التتبؤ بالمعنى من التركيب ، فهو يمكن

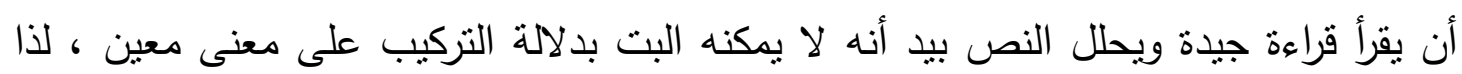

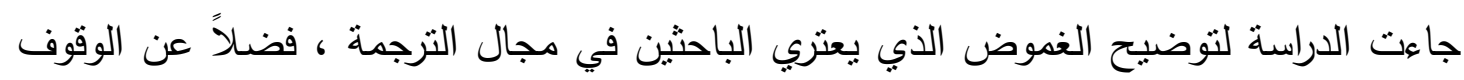

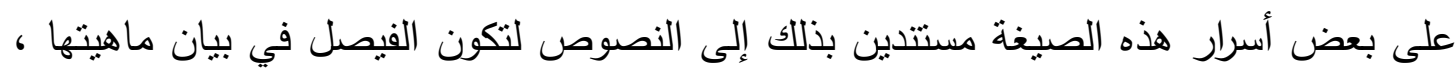

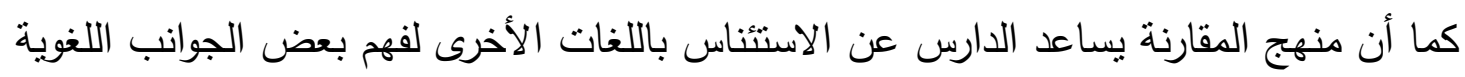

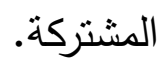
الكلمات المفتاحية: دلالية - صرفية - الاكدية - العبرية - العربية. 


\title{
The (Gt) Stem in the Akkadian Language a Semantic and Morphological Study Comparing between Hebrew and Arabic languages
}

\author{
Dr. Mustafa Mohsen Muhammad \\ Faculty of Archeology /Department of Ancient Iraqi Languages \\ mustafamehsen2@gmail.com
}

\begin{abstract}
:
The Akkadian language is rich in many forms, including the GT form. These two symbols refer to two meanings in foreign languages, especially English $(\mathrm{G})$ meaning (gerund) and $(\mathrm{t})$ represent the augmenting on the basic formula, the formula (Gt) is a natural product born from the womb of the need to expand the meanings, so when the basic formula does not meet or fails to perform a specific connotation, linguists resort to the augmenting to fill the deficiency, it is believed that these are characteristics of the mother's tongue, the Akkadian language is thus no different from its sisters from the same language family.

The choice of the subject was based on the necessity to get acquainted with this form and clarify the ambiguity surrounding it, especially since it shares the same form of the perfect verb, as the past tense (Gt) has the same morphological shape that shows the perfect,(iptaras), they both take the same form, but the intention is different, So the perfect form expresses a specific time, while the formula (Gt) has other functions that differ from the formulas of perfection. Hence the need to clarify this formula and delve into it. The researcher in ancient languages and the cuneiform reader cannot predict the meaning from the formula itself, so the study came to clarify the ambiguity facing researchers in the field of translation, as well as to know some of the secrets of this formula based on the texts, to be the decisive factor in explaining what they are, and the comparison approach helps the student to draw attention to other languages to understand some common linguistic aspects.
\end{abstract}

Keywords: Semantic , Morphology, Akkadian, Hebrew , Arabic.

تزخر اللغة الأكدية بالعديد من الصيخ المزيدة بما فيها صيغة (Gt) ويتمض هذان الرمزان الدلالة على معنيين في اللغات الأجنبية ولانيما اللغة الإنكليزية إذ أن الأول حرف (G) هو مختصر الأنا

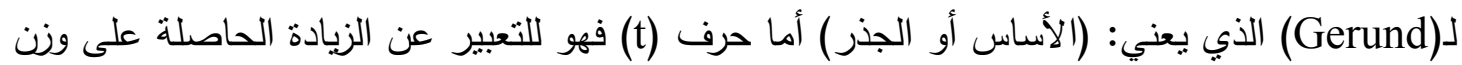


الصيغة الأساس، والصيغة (Gt) هي نتاج طبيعي ولدت من رحم الحاجة إلى التوسع في المعاني ، فحينما لا توفي الصيغة الأساس أو تقصر في أداء دلالة معينة يلجأ اللغويون إلى الزيادة على المجرد لسد النقص، ويعتقد أن هذا من خصائص اللغة الأم mother knee واللغة الأكدية بذلك لا تختلف

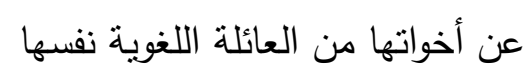
لقد جاء اختبار الموضوع بناءً على الحاجة للتعرف على هذه الصيغة وإيضاح الغموض الذي يكتنفها ولاسيماً وأنها تتشارك صرفياً مع صيغة الفعل التام ، إذ أن صيغة (Gt) الماضية لها الوزن نفسه الذي يؤدي صيغة التام وهو iptaras فكلاهما يأخذان الصيخة ذاتها غير أن القصد مختلف فصيغة التام تعبر عن زمن معين ، في حين أن صيغة (Gt) لها وظائف أخرى تختلف عن صيغ التام ،ومن هنا برزت الحاجة إلى نوضيح هذه الصيغة والخوض في مضانها ، فالباحث في اللغات القديمة وقارئ المسماريات لا يمكنه التتبؤ بالمعنى من التركيب ، فهو يمكن أن يقرأ قراءة جيدة ويحلل النص بيد أنه لا لا بهاب

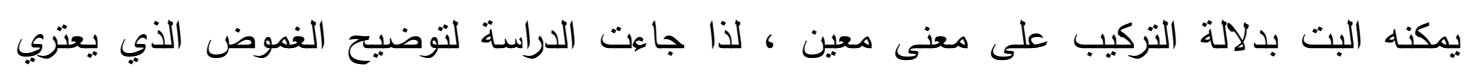

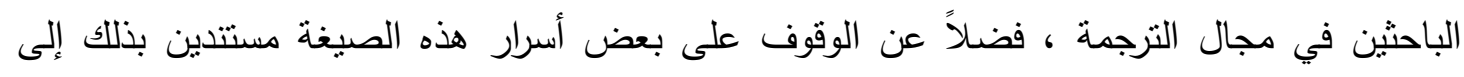

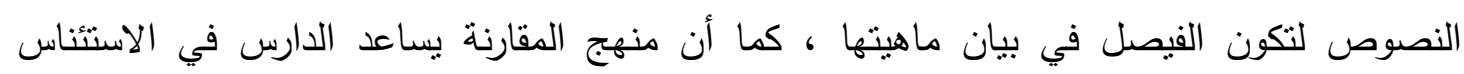
باللغات الأخرى لفهم بعض الجوانب اللغوية المشتركة.

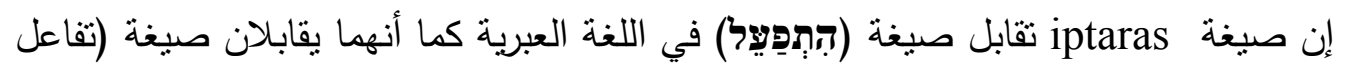
أو افتعل) في اللغة العربية لأن كلتاهما يمكن أن يؤديا المعنى ذاته ، إلا اننا وبالنظر إلى تتوع معاني

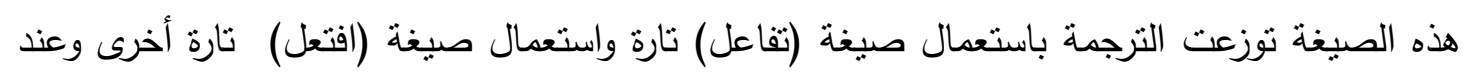

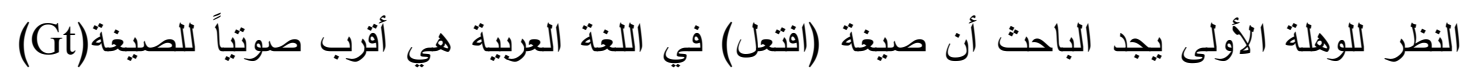

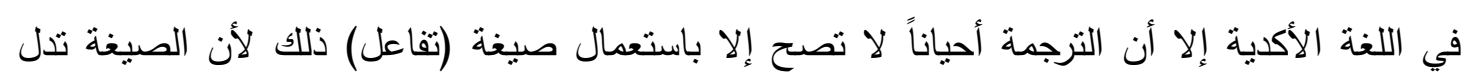
على المشاركة في الغالب، والذي بعنينا في هذا المقام أن الصبغتتين(تفاعل وافتعل) في اللغة العربية

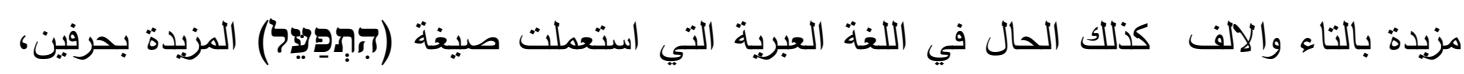
ومعلوم أن الهاء في اللغة العبرية تعامل معاملة الهمزة أو الالف في اللغة العربية خصوصا في بناء الأفعال وتعربف الاسم وهي تشبه هاء البدل في اللغة العربية نحو: هرقت وأرقت فالهاء بدل من الهمزة

وكذلك قولهم هرق

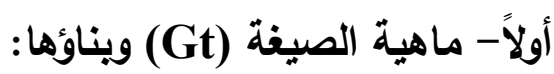

وهي واحدة من الصيخ الأكدية المزيدة والمزيد:هو ما كان بعض أحرف ماضيه زائداً عن الأصل('). والزيادة في اللغة الأكدية قد تكون بالتضعيف أي تكرار الحرف أو بزيادة حرف الثين

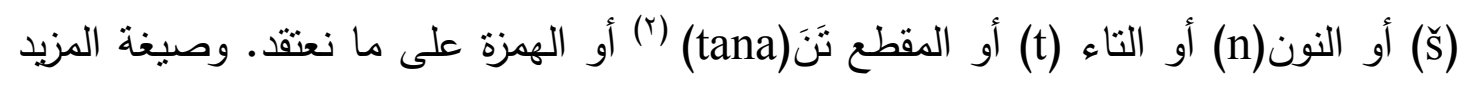
في اللغة العبرية قد تكون بالتضعيف أو بالنون (د) أو بالهاء (ه) أو بالواو ( ) أو بالتاء (ת) أو الياء (') (r). وكذلك الحال في اللغة العربية إذ تجمع أحرف الزيادة في كلمة سألتمونيها(؟). والزيادة تكون لإضافة معنى جديد(ه).والصيغة المزبدة(Gt)هي الصيغة الأولى من الصيخ الثانوية 
الأولى في اللغة الأكدية وجاءت تسميتها بال(Gt) بناء على الرموز التي وردت في كتب النحو، Gerund ( إذ أطلق الباحثون عدة تسميات على هذه الصيغ ،إذ أطلقوا على الصيغة البسيطة Double (stamm

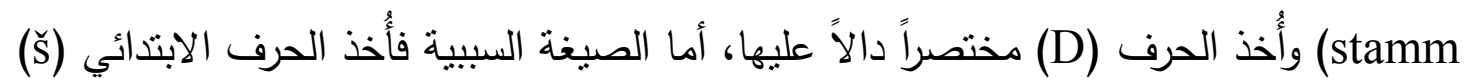
دالاً عليها، والصيغة الرابعة الحرف (N) دالاً عليها، أما الصيغ الثانوية الأولى فقد رُمز لها بالرموز الآتية: (Gt, Dt,Št) ورُمز للصيغ الثانوية الثانية بالرموز (Ntn, Štn, Dtn, Gtn) في حين استعمل عدد من الباحثين الأجانب الأرقام اللاتينية (IV, III, II, I) للصيخ الرئيسة، وللصيغ الثانوية الأولى (IV4,III3, II2, I2) والصيغ الثانوية الثانية (IV3, III3, II3, I3) وتتم صياغتها بالبدء بحرف الزيادة الهزة المكسورة(i) وبعدها الحرف الأول من جذر الفعل ثم التاء بين الحرفين الأول والثاني من جذر الصيغة وهي بذلك تأني على وزن iptaras بمعنى

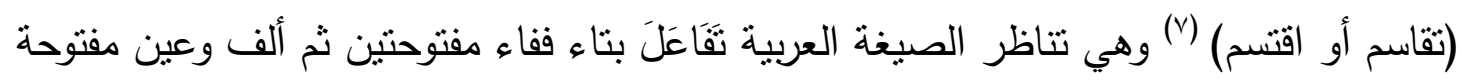

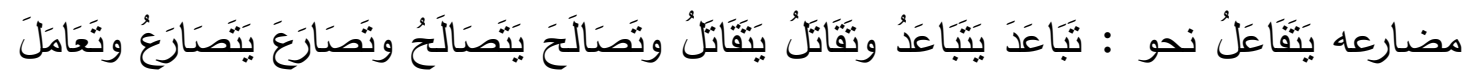

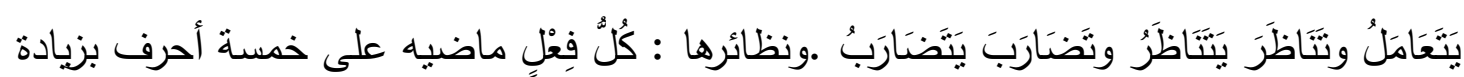
التاء في أوله والألف بين الفاء والعين .والمصدر منه على وزن واحد وهو : تَفَاعُل نحو : تَََاعَدَ

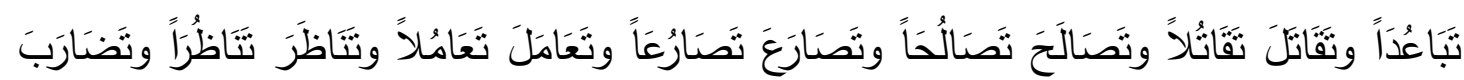

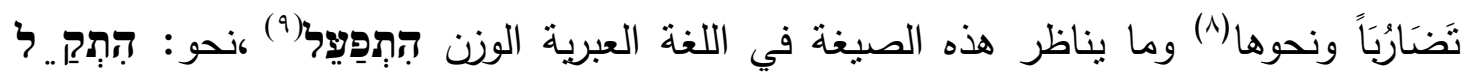
بمعنى (تقاتل) وهو يمكن أن يدل على الفاعلية والمفعولية('). وهي صيغة قد تدل على معنى المطاوعة والمشاركة ومعانٍ أخرى. ('1)

يعتمد بناء الصيغة (Gt) على نظام ثابت مشابه للصيغة الأساس (G) بالنسبة لحركة عين الفعل والتي تكون بين الحرفين التاني والثالث من جذر الفعل وهي بذلك تعتمد على باب الفعل. بقي علينا ان نذكر التغيرات الصوتية التي قد تطرأ على صيغة (Gt) وهي على النحو الآتي:

1-القلب المكاني (metathesis) وهو تغيير في ترتيب حروف الكلمة المفردة عن الصيغة المعروفة لها بواسطة تقديم بعض الحروف وتأخير بعضها الآخر ، ويحدث القلب المكاني في

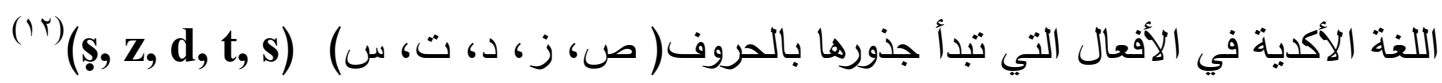

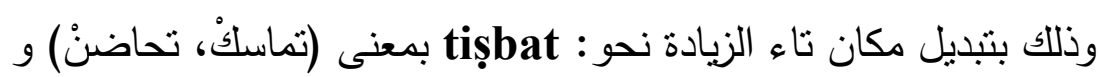
tisqar (T - 0 - ש شين - ש سين)، يحدث قلب مكاني أي تقديم وتأخير حيث تثقدم فاء الفعل

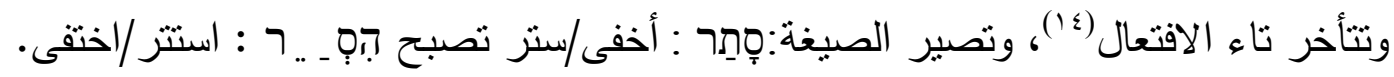

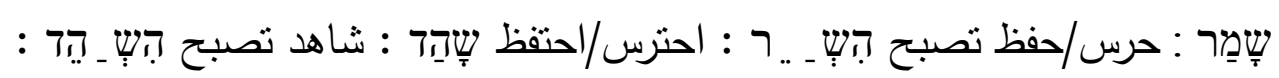


د. مصطفى محسن محمد

الصيغة المزيدة بالتاء (Gt) في اللغة الأكلية

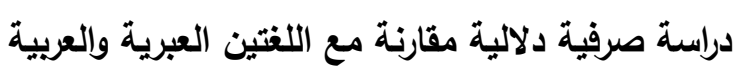

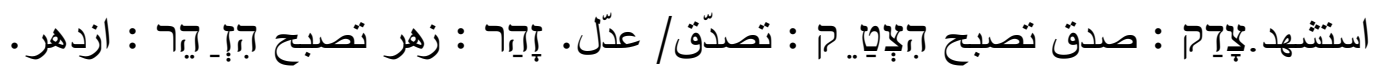

وكذلك في اللغة العربية(1) نحو:

صبر - اتصبر - اصنبر - اصطبر ، وضرب - اتضرب - اضنرب - اضطرب

ץ-الابدال: وهو جعل حرف مكان آخر لضرورة لفظية(1): إما لتسهيل النطق أو لمجاراة الصيغة الثائعة، وهو إبدال مطرد ضروري عند جميع العرب، ويقع في حروف معينة يجمعها لفظ (طال

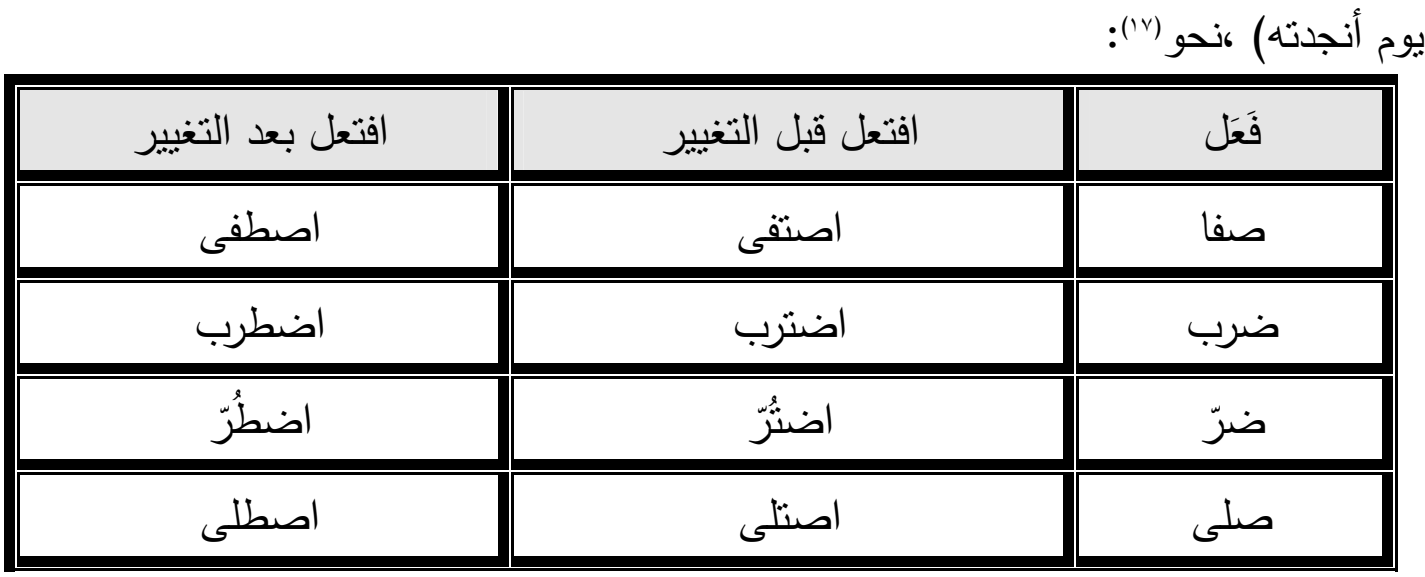

كذلك الحال في اللغة الأكدية نحو:

\begin{tabular}{|c|c|c|}
\hline الصيغة(Gt) بعد الإبدال & الصيغة(Gt) قبل الإبدال & المصدر \\
\hline igdamur & Igtamur & (كمل)gamaru \\
\hline itțarud & itṭarud & t(ارسل)țaradu \\
\hline iṣṣabat & iștabat & (ضبط)ṣabatu \\
\hline izzakur & Iztakur & (ذكر)zakaru \\
\hline
\end{tabular}

كذللك في اللغة العبرية يحدث الإبدال في هذه الصيغة، تابع التسلسل الآتي:

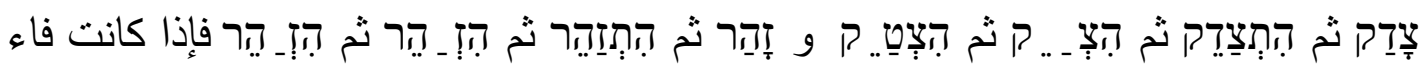
الفعل تقدّمت تاء الافتعال فأين تلك التاء؟ إننا نجد طاءً ט وليس تاء ת والواقع أن ما حدث هو

تحول وانقلاب التاء ת المرققة إلى طاء ט مفخمة.. والجواب هو أن الصاد المفخمة (צ) أثرت على جارتها التاء ת فقلبتها إلى طاء ט تقاربها أو تماثلها في التفخيم وفي الوقت نفسه تشارك وتمانل التاء التي تغيرت في المخرج فكلاهما أصوات أسنانية . 
ثانياً- كيفية التفريق بين صيغة (Gt) وصيغة الفعل التام من الصيغة الاساسية(G)

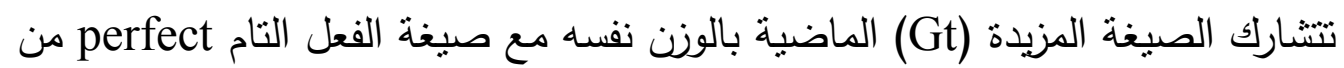

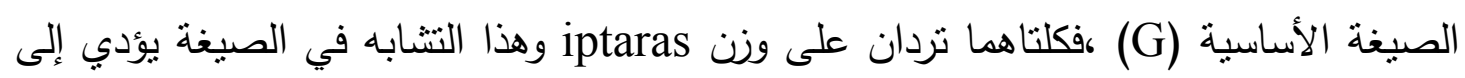

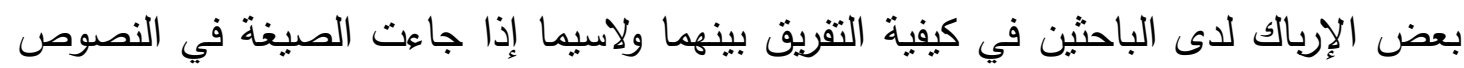

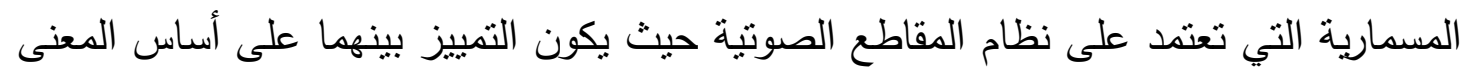

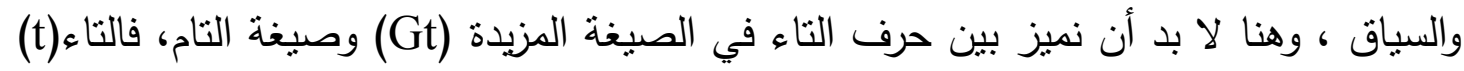

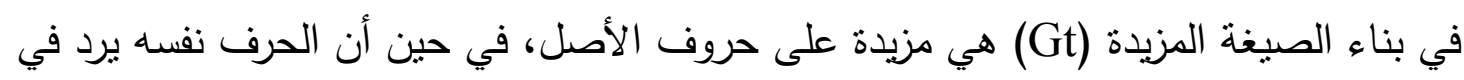

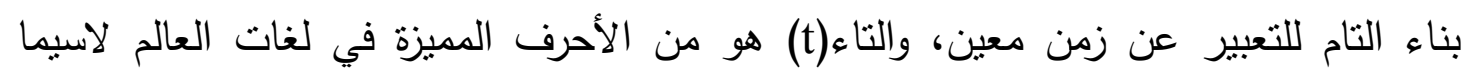

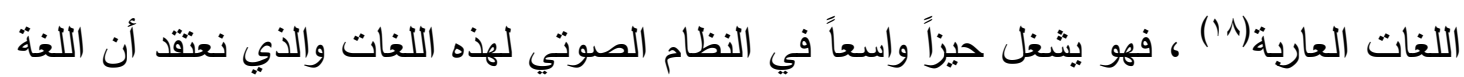
الأكدية قد ورثثه من اللغة العاربة الأم ، وفي الحديث عن اللغة الأكدية نجد أن لهذا الحرف دوراً

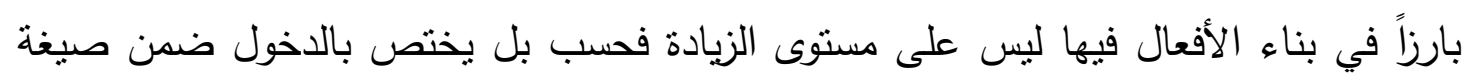

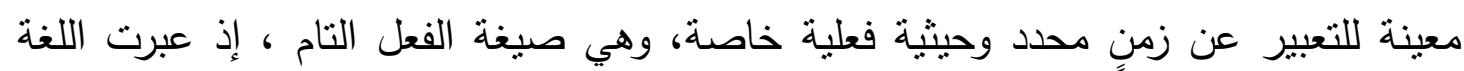

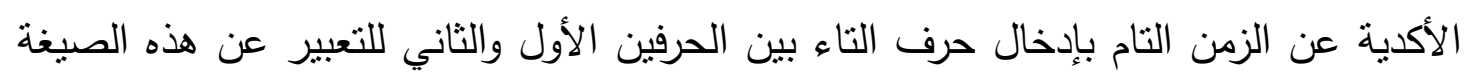

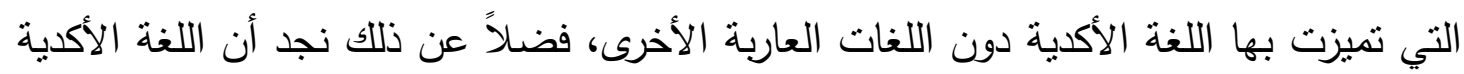

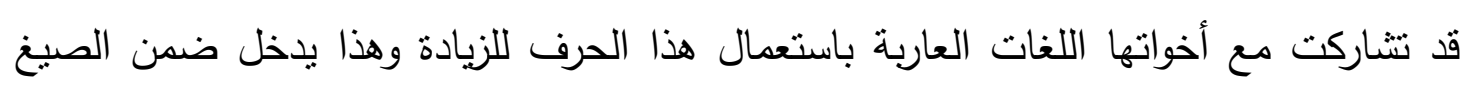
الثانوية الأولى والثانوية الثانية. كما في الجدول الآتي:

\begin{tabular}{|c|c|c|c|}
\hline \multicolumn{3}{|c|}{ بــــــاب الف ــــــل } & \multirow{2}{*}{ نوع الصيغة } \\
\hline باب الضم(u) & باب الكسر (i) & باب الفتح(a-u) & \\
\hline imtaqut & ištariq & ištakan & صيغة التام(9) \\
\hline imtaqut & ištariq & ištakan & صيغة (Gt) الماضية(r) \\
\hline
\end{tabular}

والمقصود من الكلام أنا إذا اعتمدنا على الميزان الصرفي فلا يمكننا التمييز بين الصيغتين

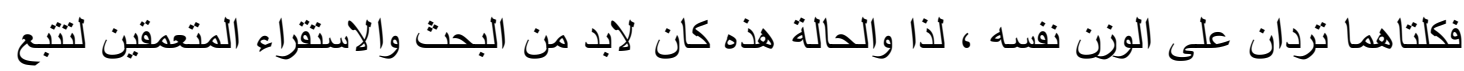

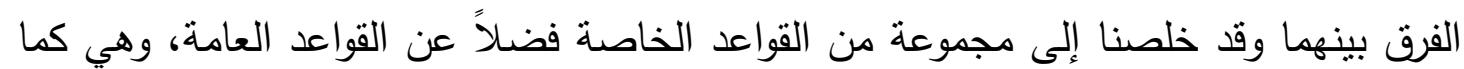
يأني:

1- يعبر الفعل التام عن أزمان معينة ووظيفته مرتبطة بالزمن وأثكاله في حين أن الصيغة المزيدة (Gt) الماضية لها دلالات معجمية تختص بها وذلك بسبب الزيادة على الثلاثي لأن

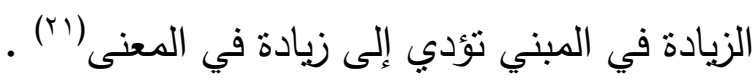




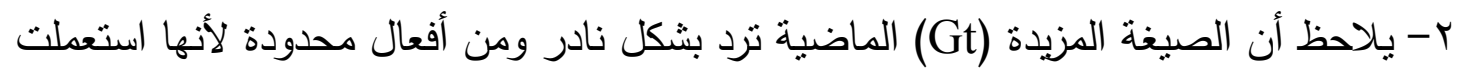

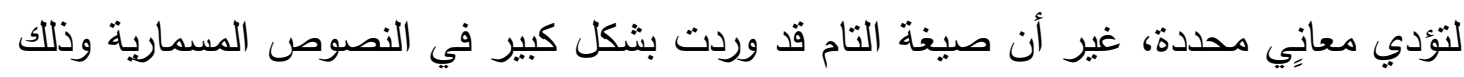
التأدية أزمنة مختلفة وعديدة. r- يمكن التمييز بين الصيغتين من معاني الجذور المعجمية إذ أن هناك أفعال يمكن أن تؤدي وعداه

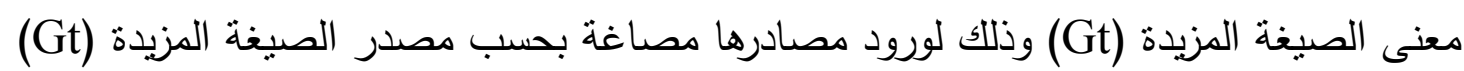

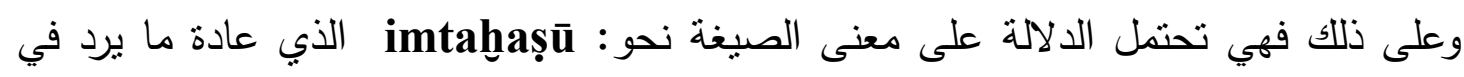
المصطلحات العسكرية بمعنى(تحاربوا ، تقاتلوا) في حين أن هناك أفعال لم ترد في الأصول

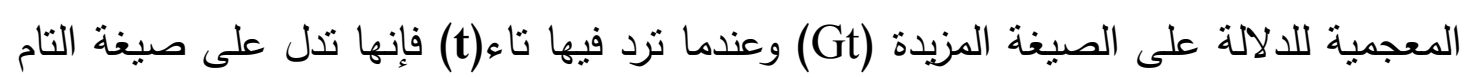

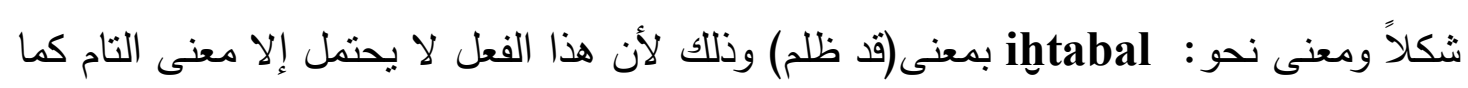

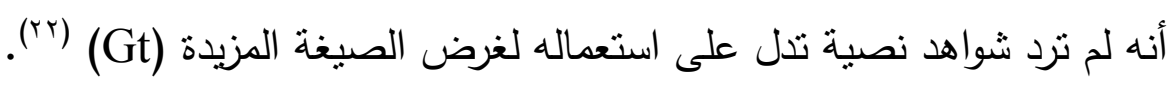

ثالثا- الصياغة والتصريف: ترد الصيغة المزيدة (Gt) في جميع الأزمنة، ومن القواعد المشتركة بين الصيغتين (Gt)

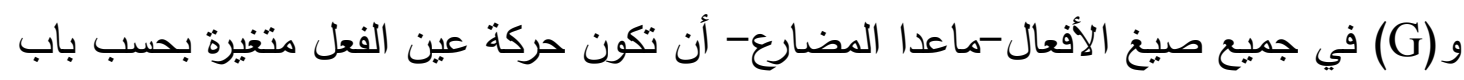

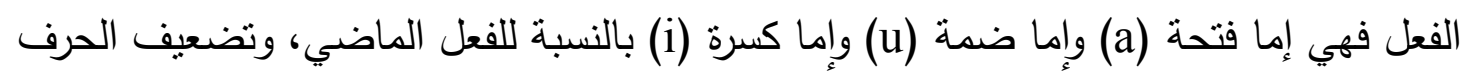
الثاني من جذر الفعل بالنسبة لصيغة الفعل المضارع وتكون حركة عين الفعل فتحة(a) فضلاًاً عن زيادة حرف التاء (t) إلى جميع تلاك الصيغ ، كما أنها تتصرف لجميع الأشخاص على على غرار الصيغ الأكدية الرئيسة وفيما يأتي عرض مفصل لصن لصياغتها وتصريفها لجميع الأزمنة

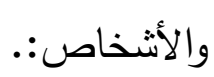
1-الماضي: يصاغ الفعل الماضي من الصيغة المزيدة (Gt) على وزن iptaras أي وفق قاعدة الزيادة بأن

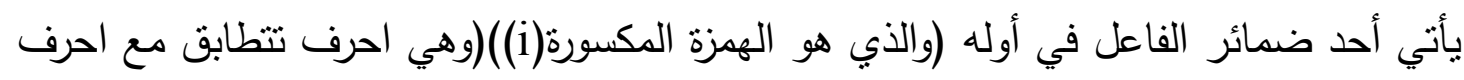

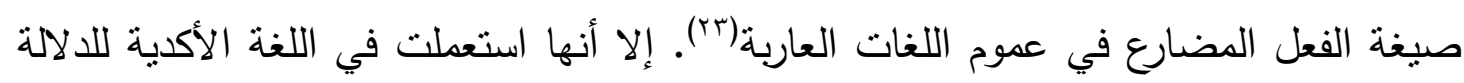

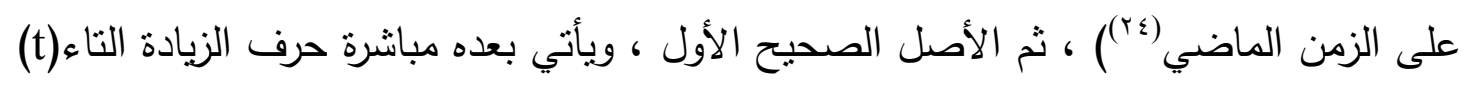

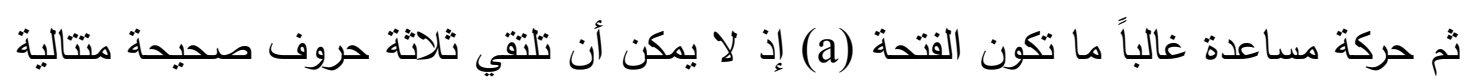

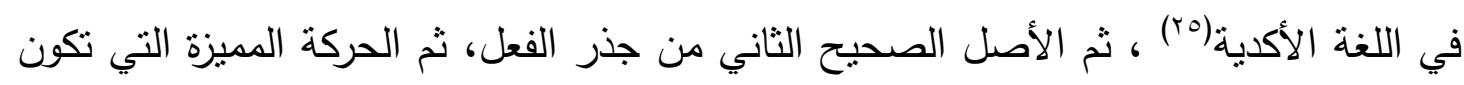

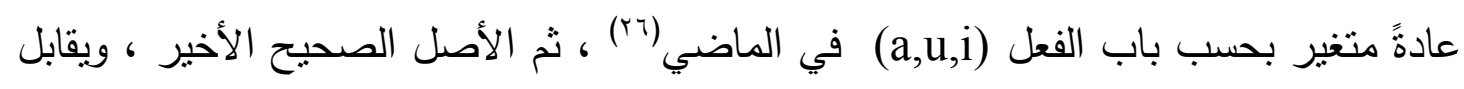

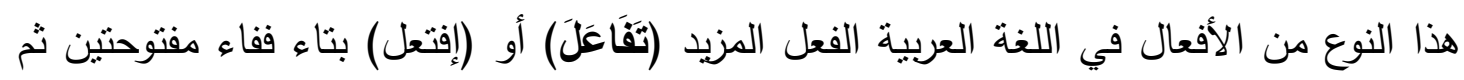

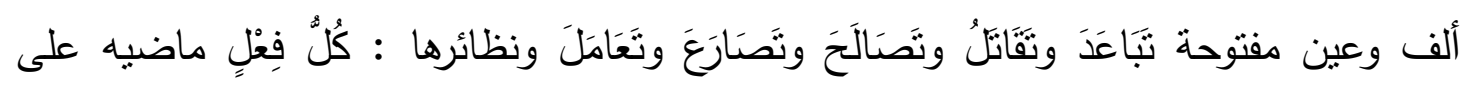


خمسة أحرف بزيادة التاء في أوله والألف بين الفاء والعين (YV)، وحكمه في فروعه جميعاً أن لا

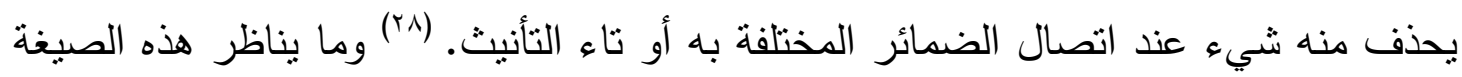

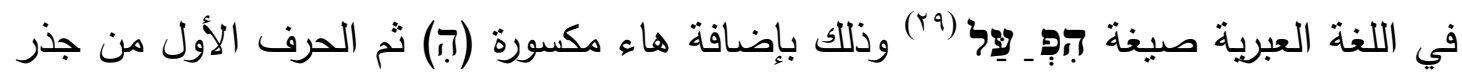

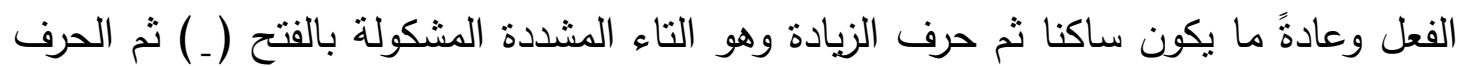
الثاني يليه الحرف الثالث.

وفيما يأتي جدول يوضح تصريف الماضي من الصيغة المزيدة بالتاء)(t)

\begin{tabular}{|c|c|c|c|c|}
\hline المعنى بالعربية & اللغة العبرية & المعنى بالعربية & اللغة الأكدية & الأشخاص \\
\hline تراسلتُ & 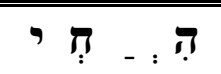 & تراسلتُ & aštapar & المتكلم \\
\hline تراسلْ & $\pi$ & تراسلْ & ištapar & الغائب \\
\hline تراسلتُ & דִ : - : דָה & تراسلتُ & ištapar & الغائبة (r) \\
\hline تتراسلْ & 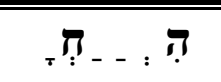 & تتراسلْ & taštapar & المخاطب \\
\hline تتراسلينَ & די : . & تتراسلينَ & taštaprī & المخاطبة \\
\hline يتراسلونَ & $\pi$ & يتراسلونَ & "ištaprū & الغائبون \\
\hline يتراسلنَ & חִ : - : ח & يتراسلنَ & ištaprā & الغائبات \\
\hline تتراسلون & 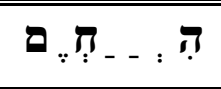 & تتراسلون & taštaprā & المخاطبون \\
\hline تتراسلن & 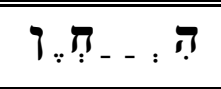 & تتراسلن & taštaprā & المخاطبات \\
\hline تراسلنا & 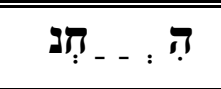 & تراسلنا & ništapar & المتكلمون \\
\hline
\end{tabular}

ومن ملاحظة الجدول السابق نرى أن هناك بعض التغيرات الصوتية التي تحدث في بعض الأفعال .ففي اللغة الأكدية يلاحظ سقوط حركة عين الفعل عند إضافة لاحقة الأشخاص ونعتقد أن السبب وراء ذللك هو لتخفيف النطق وعدم التكلف في اللفظ. كما أن هذا الأمر ينطبق على اللغة العبرية حيث تحدث بعض التغيرات في الصيغة وذلك بحسب قواعد النظام الصوتي لها.

1-المضارع:

يصاغ الفعل المضارع من الصيغة المزيدة(Gt) على وزن iptarras وهو على غرار ما يصاغ من الصيغة البسيطة(G) إذ تبدأ الصيغة بحرف المضارعة الياء(i) ثم الأصل

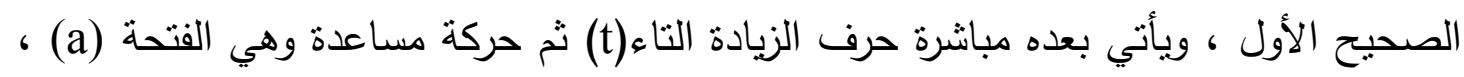




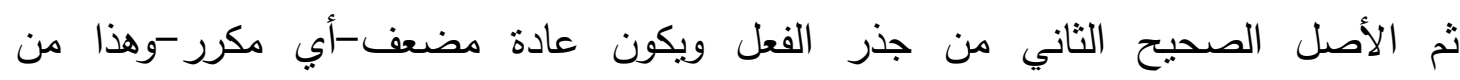

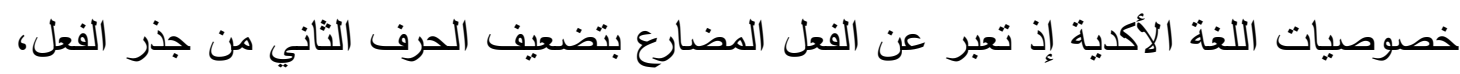

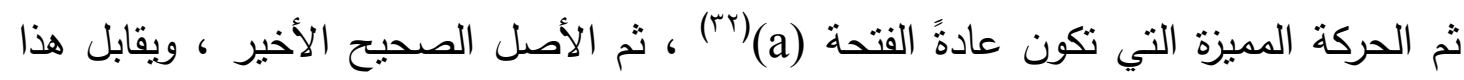

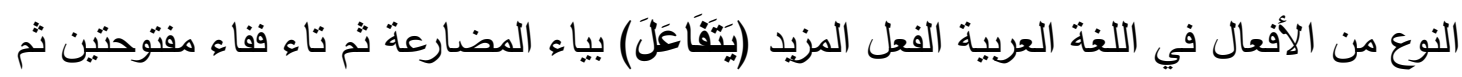

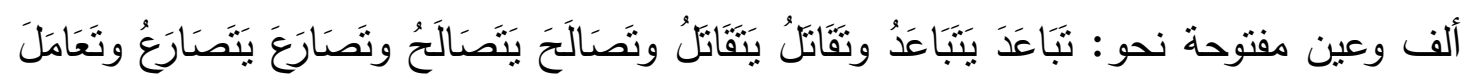

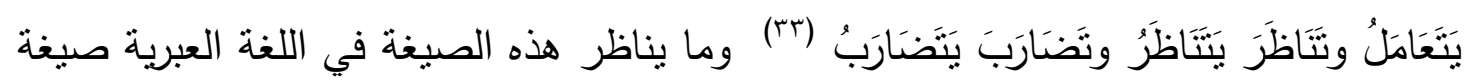

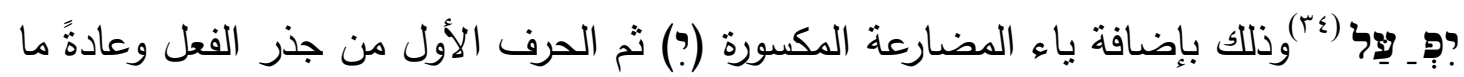

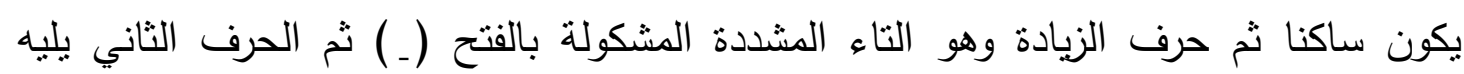
الحرف الثالث. وفيما يأتي جدول يبين أوجه التصريف.

\begin{tabular}{|c|c|c|c|c|}
\hline المعنى بالعربية & اللغة العبرية & المعنى بالعربية & اللغة الأكدية & الأشخاص \\
\hline اتقاتل & 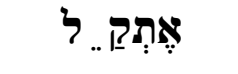 & اتقاتل & amtahbas & المتكلم \\
\hline يتقاتل & 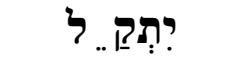 & يتقانل & imtahhaș & الغائب \\
\hline تثقاتل & 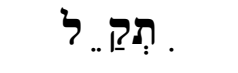 & تنقاتل & imtahhhas & الغائبة \\
\hline تثقاتل & תחקָ. לל & تتقاتل & tamtahbhaș & المخاطب \\
\hline تتقاتلين & 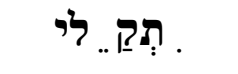 & تتقاتلين & tamtaḩhaṣī & المخاطبة \\
\hline يتقاتلون & יתחקה :לי & يتقاتلون & imtahhhașū & الغائبون \\
\hline يتقاتلن & 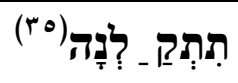 & يتقاتلن & imtaḩhaṣā & الغائبات \\
\hline تثقاتلون & תחתחקָ : ל & تثقاتلون & tamtahhhașā & المخاطبون \\
\hline تتقاتلن & 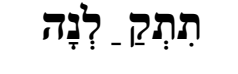 & تتقاتلن & tamtaḩhaṣā & المخاطبات \\
\hline نتقاتل & 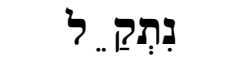 & نتقاتل & nimtaḩhaṣ & المتكلمون \\
\hline
\end{tabular}

ويلاحظ أن هناك تثابه بين المخاطبات والمخاطبين في الأكدية حيث أخذتا الناحقة(a)

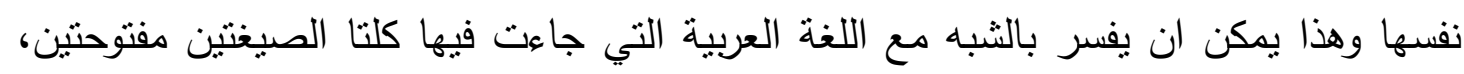
كذلك نرى المخاطبات والغائبات في اللغة العبرية ينتابهان ولا يمكن التفريق بينهما إلا على بلى أساس المعنى والسياق. : perfect يصاغ الفعل التام من الصيغة المزيدة (Gt) على وزن iptataras وذلك أن نبدأ بحرف الهمزة المكسورة (i) وبعدها الحرف الأول من جذر الفعل ثم تاء مفتوحة (ta) التي هي خاصنة 
بالتام ومن ثم تاء الزيادة وعادة ما تكون ساكنة إذ يليها مباشرة الحرف الثاني من جذر الفعل وتكون حركة عين الفعل على غرار الصيغة المجردة (G) أبي أنها متغيرة بحسب تغير باب الفعل فهي إما الفتحة (a) وإما الضمة(u) وإما الكسرة(i) وتقيد هذه الصيغة تقربب الزمن الماضي من الزمن الحاضر ، ويقابلها في اللغة العربية صيغة (قد تفاعل) لأن الحرف (قد) يفيد

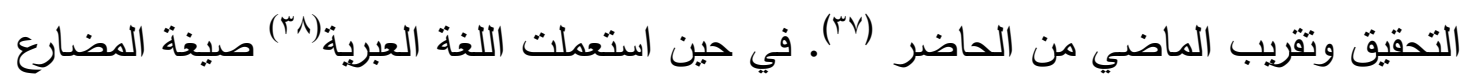
مع واو القلب للتعبير عن هذا الزمن(9") ، ونحن بذلك نرى أن اللغة الأكدية من حيث استعمال هذه الصيغة هي أكثر فصاحة لأنها مالت إلى الاختصار للتعبير عن زمن معين وهذا مما

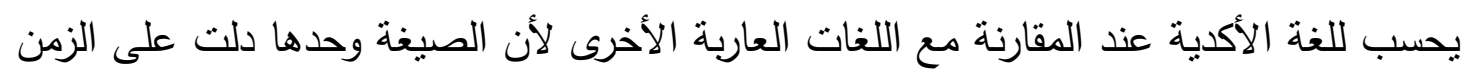
المنشود في الوقت الذي احتاجت فيه اللغتان العربية والعبرية إلى القرائن اللفظية للتعبير عن زمن التام فهي بذلك تتدرج تحت قاعدة (ما بؤدي المعنى في نفسه أولى بأن يكون أصلا لما يحتاج إلى غيره) وفيما يأتي جدول يوضح تصربف هذه الصيغة وفق هذا الوزن.

\begin{tabular}{|c|c|c|}
\hline المعنى بالعربية & اللغة الأكدية & الأشخاص \\
\hline قد تساقطت & amtatqut & المتكلم \\
\hline قد نساقط & imtatqut & الغائب \\
\hline قد تساقطت & imtatqut & الغائبة \\
\hline قد تساقطتَ & tamtatqut & المخاطب \\
\hline قد تساقطتِ & tamtatqutī & المخاطبة \\
\hline قد تساقطوا & imtatqutū & الغائبون \\
\hline قد تساقطنَ & imtatqutā & الغائبات \\
\hline قد تساقطتم & imtatqutā & المخاطبون \\
\hline قد تساقطننَّ & imtatqutā & المخاطبات \\
\hline قد تساقطنا & nimtatqut & المتكلمون \\
\hline
\end{tabular}

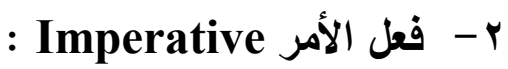

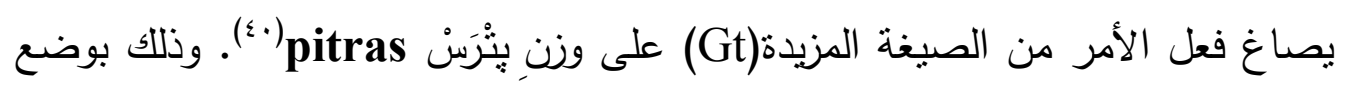
الحرف الأول الصحيح من جذر الفعل ثم كسرة(i). وبعدها التاء(t) يليهِ الحرف الثاني من جذر الفعل ثم حركة عين الفعل وتكون متغيرة بحسب باب الفعل فهي أما فتحة(a) أو ضمة(u) أو كسرة(i)، فيمكن أن يصرف فعل الأمر في عموم اللغات العاربة ومنها الأكدية(اء). والعبرية(rع). 
د. مصطفى محسن محمد الصيغة المزيدة بالتاء (Gt) في اللغة الأكلية

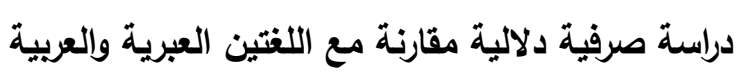

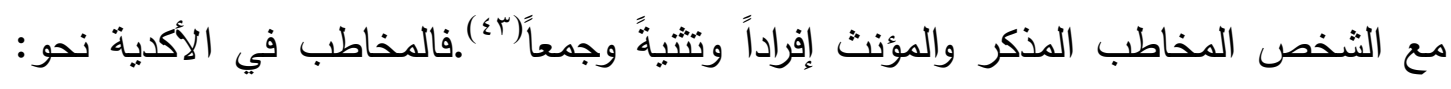
pitras الأمر للمخاطب المفرد المؤنث في اللغة الأكدية تسند ياء المخاطبة (1)) إلى فعل الأمر نحو:

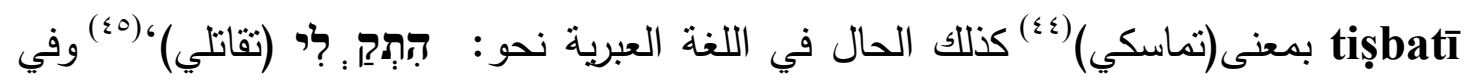
اللغة العربية نحو تعاوني وتصالحي. في حين استعملت اللغة الأكدية صيغة واحدة للمخاطب

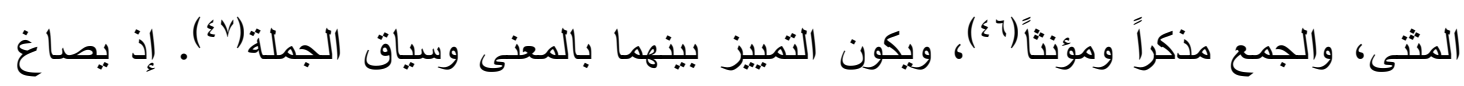

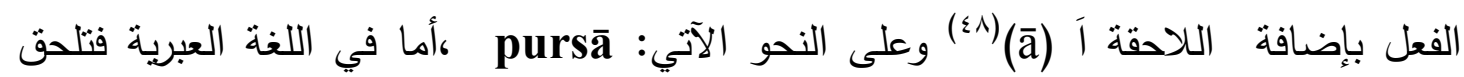

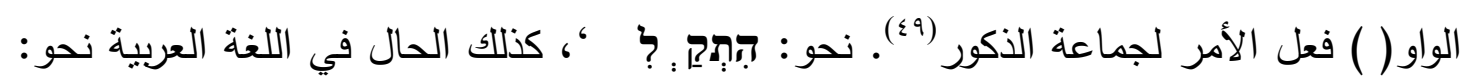
تتافسوا وتصالحوا، وهي مشابهة للغة العبرية في هذه اللاحقة. أما عند صياغته لجماعة الإناث

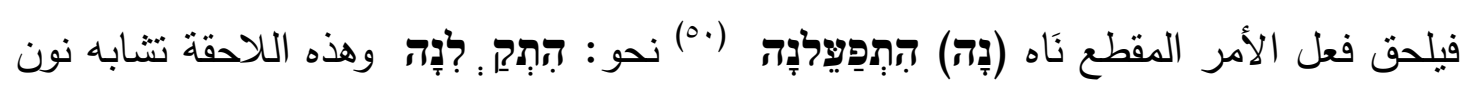

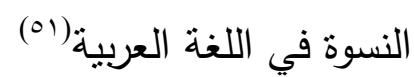

\begin{tabular}{|c|c|c|c|}
\hline $\begin{array}{l}\text { باب كسر -كسر } \\
\text { šaraqu(i-i) }\end{array}$ & باب ضم -ضم & 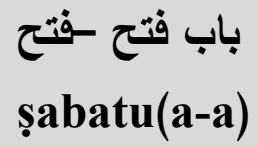 & الأشخاص \\
\hline šitriq & mitqut & tiṣbat & المخاطب \\
\hline šitriq̄ī & mitqutī & tiṣbatī & المخاطبة \\
\hline šitriq $\overline{\mathbf{a}}$ & mitqutā & tiṣbatā & المخاطبون \\
\hline$\overline{(\circ r)}$ šitriqā & mitqutā & tiṣbatā & المخاطبات \\
\hline
\end{tabular}

ومن الثواهد عليها نقرأ:

\begin{tabular}{|l||l|}
\hline ti- iṣ-ba-ri $^{(53)}$ & تحادثي معي' \\
\hline
\end{tabular}

ويلاحظ في هذا المثال أن حرف الزبادة تَ (ta) قد جاءت في أول صيغة فعل الأمر، وذلك فقط في الأفعال التي يكون الحرف الأول من جذرها ص، ز، د، ت، س (s, z, d, t, s) نحو هون ${ }^{(\circ)}$.tisqar g tiṣbat رابعا: دلالات ومعاني صيغة (Gt):

سبق أن ذكرنا أن الزيادة في المبنى تقابلها زيادة في المعنى لذا فان الصبغة (Gt) قد استعملها الأكديون للالالة على معان عجزت الصيغة الأساس أن تؤديها مما دفعهم للانتقاع من الأوزان المزيدة لتلبية المعاني المرادة ومن هنا انبتقت جملة من المعاني التي عبرت عنها صبغة الزيادة (Gt) مع العلم أنها من الصيغ النادرة الورود وهي تشكل نسبة قليلة نوعا ما قياسا مع الأوزان المجردة من جذور الأفعال التي تزخر فيها اللغة الأكدية ، وحتى وأن استعملتها اللغة 
الأكدية على نطاق محدود من الأفعال إلا أن الثواهد في النصوص المسمارية قليلة الورود

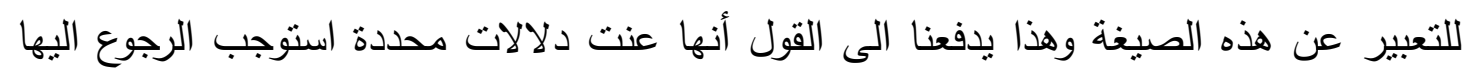
لتأدية المعنى المنشود، وفيما يأتي مجموعة من المعاني التي عبرت عنها لأنها اللغة الأكدية باستعمال

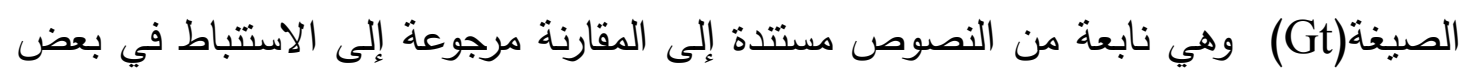

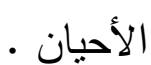

$$
\text { 1-المشاركة أو التشريك: }
$$

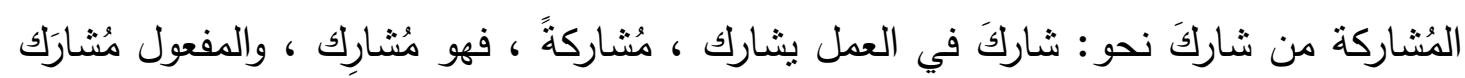

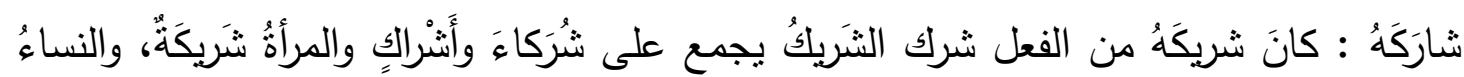

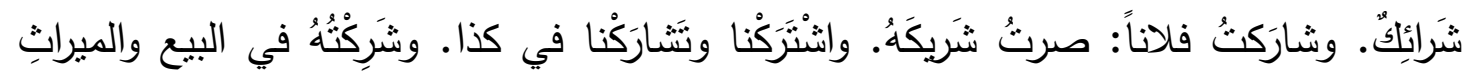

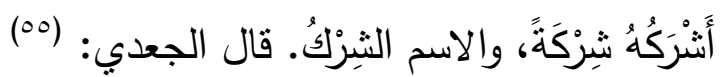

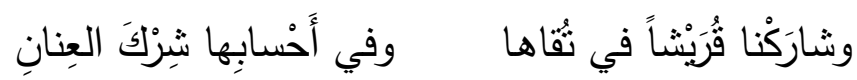
ففي اللغة العربية يدل الوزن (تفاعل)على معنى المشاركة نحو: تخاصم زيد وفئن وعمرو وتصالح القوم .وقد تؤدي الصيغة(Gt) في اللغة الأكدية(10) هذا المعنى ومن الثواهد نقرأ:

\begin{tabular}{|c|c|}
\hline اللغة الأكدية بالحرف اللاتيني & المعنى في اللغة العربية \\
\hline $\mathrm{PN}$ u PN${ }_{2}$ ahameš il-te-mu-ú ${ }^{(57)}$ & تصالح س و ص \\
\hline
\end{tabular}

$$
\text { اللغة الأكدية بالحرف اللاتيني }
$$$$
\text { المعنى في اللغة العربية }
$$
mārē RN aššum šarrutim im-taha-șu ${ }^{(58)}$

اللغة الأكدية بالحرف اللاتتيني

šarrū illunimma iš-tan-na-nu-ma māta ušahrabu ${ }^{(59)}$
المعنى في اللغة العربية

\begin{tabular}{|c|c|}
\hline اللغة الأكدية بالحرف اللاتيني & المعنى في اللغة العربية \\
\hline $\begin{array}{l}\text { iș-șa-ab-tu-ma kima le-i-im i-lu- } \\
\mathrm{du}(60)\end{array}$ & تشابك (كلكاميش وانكيدو )وانحنيا منت \\
\hline
\end{tabular}

طغى الملوك وتنازعوا واخربوا الارض 
د. مصطة محسن محمد مصن الصيغة المزيدة بالتاء (Gt) في اللغة الأكدية دراسة صرفية دلالية مقارنة مع اللغتين العبرية والعربية

\begin{tabular}{|c|c|}
\hline اللغة الأكدية بالحرف اللاتيني & المعنى في اللغة العربية \\
\hline $\begin{array}{l}{ }^{\mathrm{d} D U M U . N U N . N A} \quad \text { itti } \\
\text { Nirgal iš-šak-kan ši-tul-tum }\end{array}$ & ونتركاصح الآلهة الأبناء مع الإلهين سين \\
\hline
\end{tabular}

\begin{tabular}{|c|c|}
\hline اللغة الأكدية بالحرف اللاتيني & المعنى في اللغة العربية \\
\hline $\begin{array}{l}\text { ina šadi...ittešunu am-da-hi-is } \\
\text { dabdāšunu aškun }\end{array}$ & فوقهربت معهم في الجبال وهدمت دفاعاتهم \\
\hline
\end{tabular}

نلاحظ في الأمثلة السابقة أن اللغة الأكدية قد عبرت عن معنى المشاركة باستعمال الصيغة(Gt)

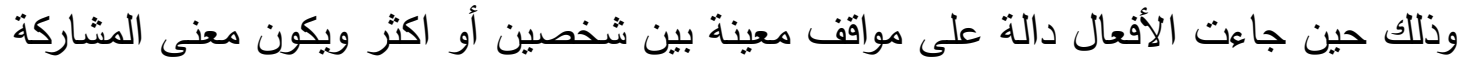

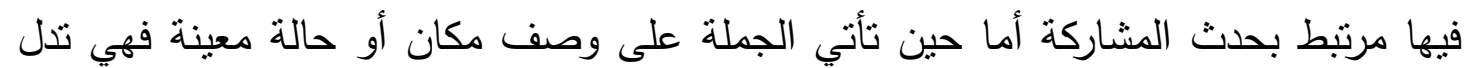
على التتاظر ومن الثواهد عليها نقرا:

\begin{tabular}{|c|c|}
\hline اللغة الأكدية بالحرف اللاتيني & المعنى في اللغة العربية \\
\hline $\begin{array}{l}\text { šumma seêr hašim si-PI-tum Á.ZI- } \\
\text { ú Á.GÜB it-ta-at-la }{ }^{(63)}\end{array}$ & إلذائة تقابل الجزءان اليمين واليسار من خلفية \\
\hline
\end{tabular}

\begin{tabular}{|c|c|}
\hline اللغة الأكدية بالحرف اللاتتيني & المعنى في اللغة العربية \\
\hline rub'ù ina barišunu [i]-ta-țù-lu $^{(64)}$ & تقابل الأمراء عن كثب \\
\hline
\end{tabular}

عند التمحيص في النصوص السابقة نرى أنها تعبر عن معنى المشاركة في وصف الحال

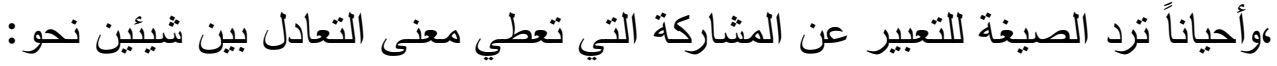

\begin{tabular}{|c|c|}
\hline اللغة الأكدية بالحرف اللاتيني & المعنى في اللغة العربية \\
\hline $\begin{array}{l}\text { ŠE.NUMUN GUD.HI.A it-ta-ța- } \\
l^{\left(u^{65)}\right.}\end{array}$ & 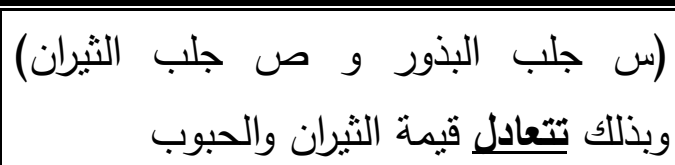 \\
\hline
\end{tabular}




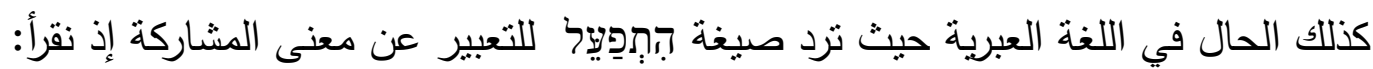

\begin{tabular}{|c|c|}
\hline 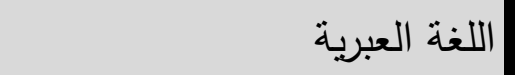 & المعنى في اللغة العربية \\
\hline 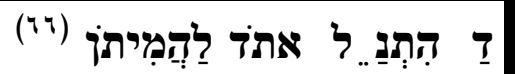 & ويتآمروا عليه ليقتلوه \\
\hline
\end{tabular}

\begin{tabular}{|c|c|c|}
\hline & اللغة العبرية & المعنى في اللغة العربية \\
\hline נ לְנ יִצֶת" & 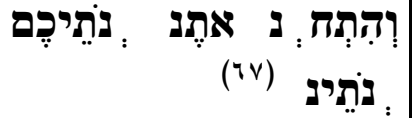 & تصاهروا معنا تعطونا بناتكم ونعطيكم بناتتا \\
\hline
\end{tabular}

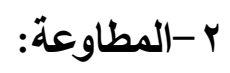

هي حصول الأثر عن تعلق الفعل المتعدي بمفعوله، نحو: كسرت الإناء فتكسر، فيكون تكسر مطاوعاً، أي مواققاً لفاعل الفعل المتعدي، وهو كسرت، لكنه يقال لفعل يدل عليه: مطاوع،

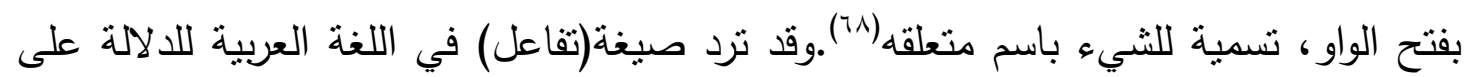
هذا المعنى نحو: عاملت زبدا فتعامل(ج9).كذلك الحال في اللغة الأكدية(•(v) فقد ترد صيغة(Gt) للالالة على معنى المطاوعة نحو:

\begin{tabular}{|c|c|}
\hline اللغة الأكدية بالحرف اللاتيني & المعنى في اللغة العربية \\
\hline $\begin{array}{l}\text { šamnam ip-ta-ša-aš-ma } \\
\text { awilišĩ } \overline{1} w e^{(71)}\end{array}$ & ادهن(دهن نفسه) وتحول إلى رجل حضاري \\
\hline
\end{tabular}

\begin{tabular}{|c|c|}
\hline اللغة الأكدية بالحرف اللاتيني & المعنى في اللغة العربية \\
\hline $\begin{array}{l}\text { qibīt šamaš u Adad bēlē bīri at-ta- } \\
\text { '-id-ma mārtu sīt libbi-ia ana } \\
\text { enūti assima }{ }^{(72)}\end{array}$ & تماثلت لأوامر شينت شادد آلهة الأقدار \\
\hline
\end{tabular}

\begin{tabular}{|r||r|}
\hline المعنى في اللغة العربية & الأكدية بالحرف اللاتيني القهر في الرابع والعشرين من الثهر \\
\hline \hline UD.2u.KAM Sin i-tab-bal-ma(73) & اللغية \\
\hline
\end{tabular}

\begin{tabular}{|c|c|}
\hline اللغة الأكدية بالحرف اللاتيني & المعنى في اللغة العربية \\
\hline $\begin{array}{l}\text { akpud at-ta-id-ma ana leqe DN } \\
\text { ana GN panīšu aškun }{ }^{(74)}\end{array}$ & 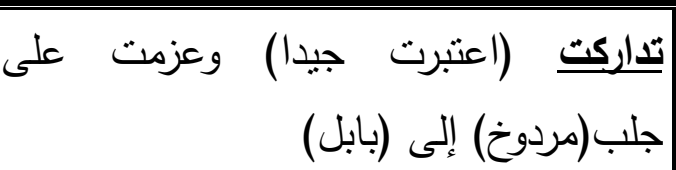 \\
\hline
\end{tabular}




\begin{tabular}{|c|c|}
\hline اللغة الأكدية بالحرف اللاتيني & المعنى في اللغة العربية \\
\hline $\begin{array}{l}\text { eli rigmēšina at-ta-a-ad-ir [ina] } \\
\text { huburšina la ișabbatanni šittu }{ }^{(75)}\end{array}$ & 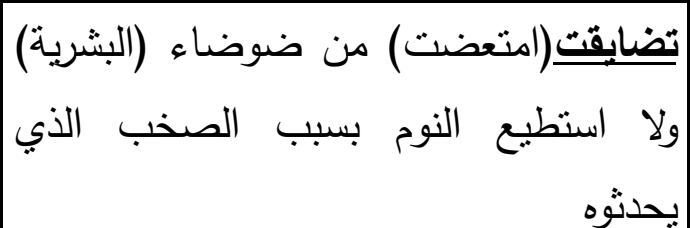 \\
\hline
\end{tabular}

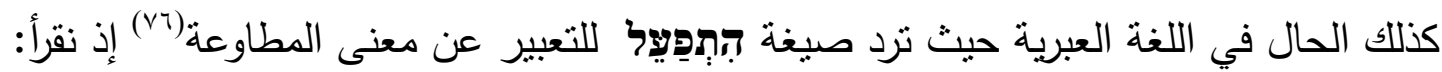

\begin{tabular}{|c|c|}
\hline اللغة العبرية & المعنى في اللغة العربية \\
\hline 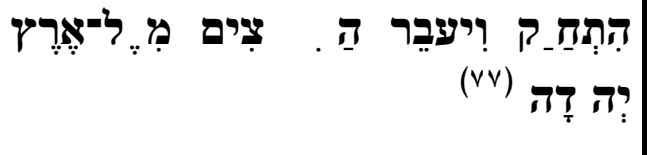 & 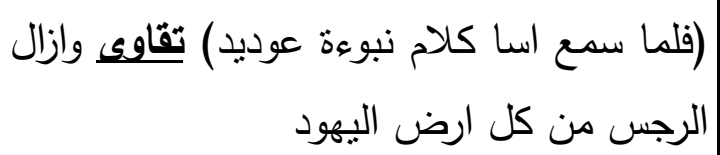 \\
\hline
\end{tabular}

\begin{tabular}{|c|c|}
\hline اللغة العبرية & المعنى في اللغة العربية \\
\hline 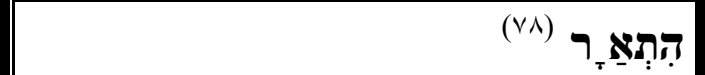 & تأزيد (اتزر بحزام) \\
\hline
\end{tabular}

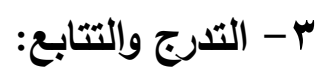

تدرَّجَ:درَّجَ إلىى العلا تدرَّجَ في الرنبة، يتدرَّج ، تدرُّجًا ، فهو مُنَدَرِج ، والمفعول مُنَتَرَّج إليه

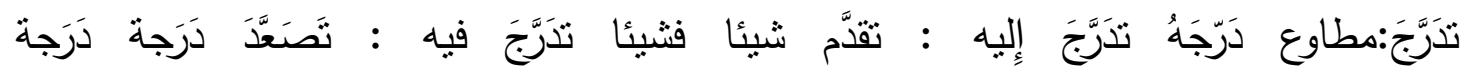

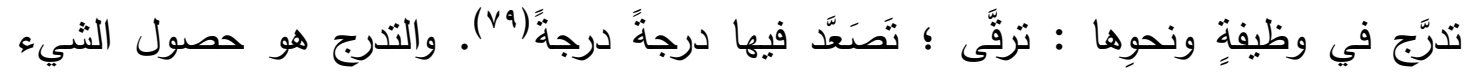
تدريجيا وهو من المعاني التي تؤديها صيغة (تفاعل) في اللغة العربية ، تقول تزايد النيل ،

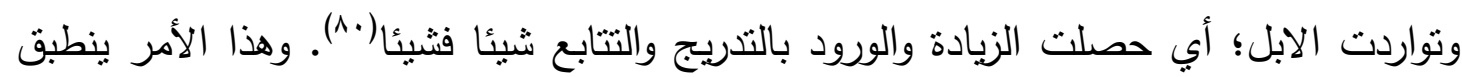
على اللغة الأكدية إذ نراها قد استعملت صيغة(Gt) للالالة على هذا المعنى حيث نقرأ:

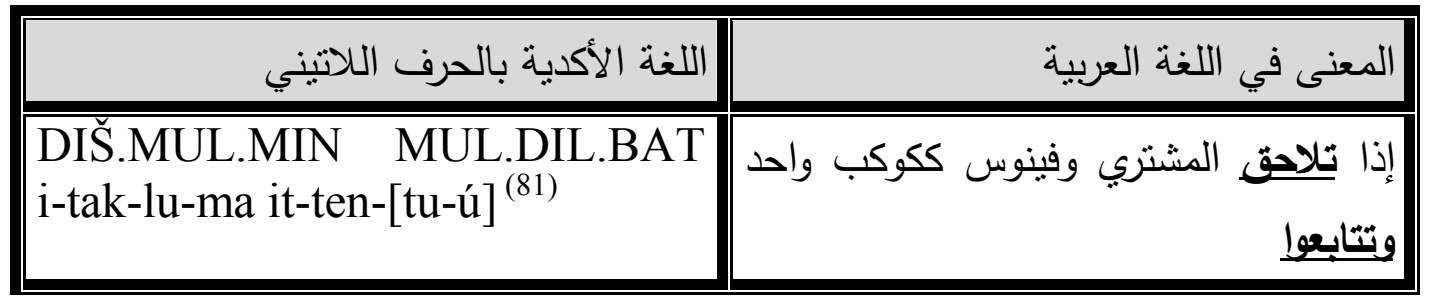

\begin{tabular}{|c|c|}
\hline اللغة الأكدية بالحرف اللاتيني & المعنى في اللغة العربية \\
\hline $\begin{array}{lcl}\text { rakabi } & \text { šumma } & \text { immeru } \\
\text { UMBIN.MEŠ rit-kub } & & \end{array}$ & إذا إسبحت ظلوف النعجة متراكبة \\
\hline
\end{tabular}




\begin{tabular}{|c|c|}
\hline اللغة الأكدية بالحرف اللاتيني & المعنى في اللغة العربية \\
\hline šumma 2 MÁŠ ir-ta-di-a ${ }^{(83)}$ & إذا تثابع جنديان (أي تبع الثاني الأول) \\
\hline
\end{tabular}

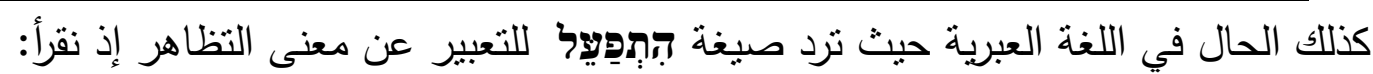

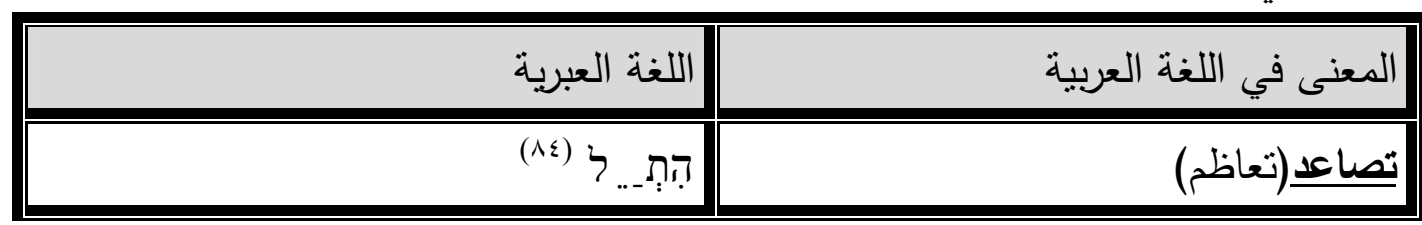

أي كبر شيئا فنشيئا

\begin{tabular}{|r||r|}
\hline المعنى في اللغة العربية & العبرِية \\
\hline \hline
\end{tabular}

أي دخل بالمرض تدريجياً كما أنها لا تخلو من طعم المطاوعة والتظاهر .

ع - التظاهر

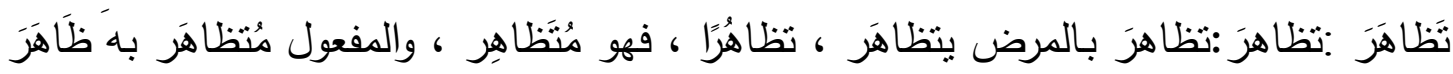

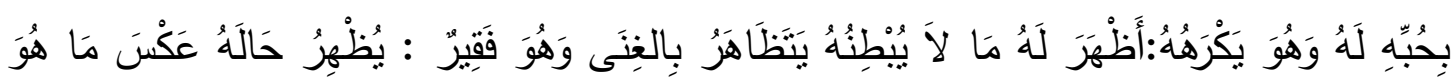

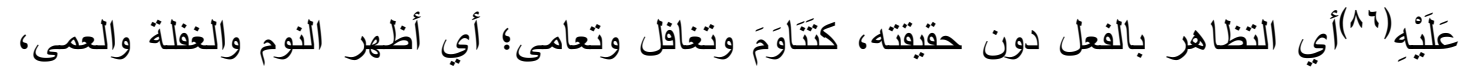

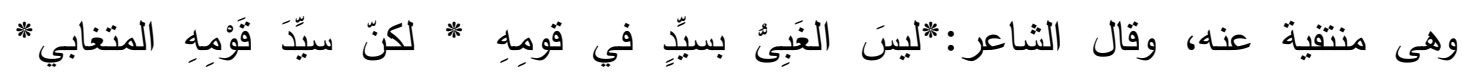

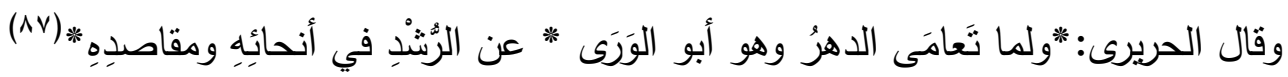
كذلك الحال في اللغة الأكدية إذ نقرأ:

\begin{tabular}{|c|c|}
\hline اللغة الأكدية بالحرف اللاتيني & المعنى في اللغة العربية \\
\hline $\begin{array}{l}\text { miššum kaspam iltanaqe-ma } \\
\text { attun ta-áš-ta-pu-a-ni }\end{array}$ & ما هذا الثيء ؟ ينتهب الفضة وانتت تتغافلوا \\
\hline
\end{tabular}

\begin{tabular}{|r||r|}
\hline اللغة الأكدية بالحرف اللاتيني & المعنى في اللغة العربية \\
\hline \hline ištu libbi-ia e-te-li(8) & اللغيته ذاكرتية \\
\hline
\end{tabular}

\begin{tabular}{|c|c|}
\hline اللغة الأكدية بالحرف اللاتيني & المعنى في اللغة العربية \\
\hline $\begin{array}{l}\text { paqu ip-te-eq-ma inatțal } u \\
\text { ippallas }^{(90)}\end{array}$ & 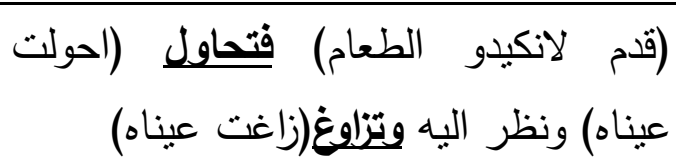 \\
\hline
\end{tabular}


د. مصطفى محسن محمد الصيغة المزيدة بالتاء (Gt) في اللغة الأكدية دراسة صرفية دلالية مقارنة مع اللغتين العبرية والعربية

\begin{tabular}{|c|c|}
\hline اللغة الأكدية بالحرف اللاتيني & المعنى في اللغة العربية \\
\hline $\begin{array}{l}\text { šit-ra-ah ina maḩar ilī-ma } \\
\text { gašru }^{(91)}\end{array}$ & تعالى (متفاخر) أمام الآلهة العظام \\
\hline
\end{tabular}

\begin{tabular}{|r|r|}
\hline التأمل شكلى في اللغة العربية الأكدية بالحرف اللاتينية & \\
\hline \hline ip-ta-ar šiknassa & \\
\hline
\end{tabular}

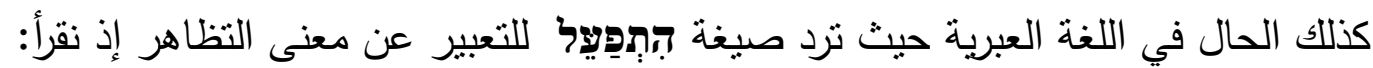

\begin{tabular}{|c|c|}
\hline اللغة العبرية & المعنى في اللغة العربية \\
\hline הִ : . _ח & تخاسي \\
\hline
\end{tabular}

\begin{tabular}{|c|c|}
\hline اللغة العبرية & المعنى في اللغة العربية \\
\hline 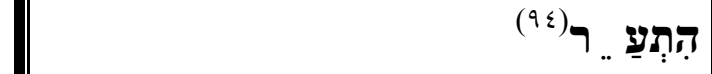 & تغانى(تظاهر بالغنى) \\
\hline
\end{tabular}

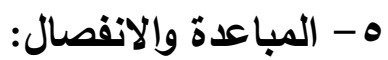

باعدَ يباعد ، مُبَاعَدةً وبِعادًا ، فهو مُباعِد ، والمفعول مُباعَد بَاعَدَهُ لِمَكْرِهِ : أبْعَدَهُ بَاعَدَهُ وَلَمْ

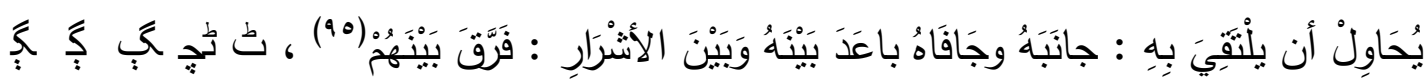

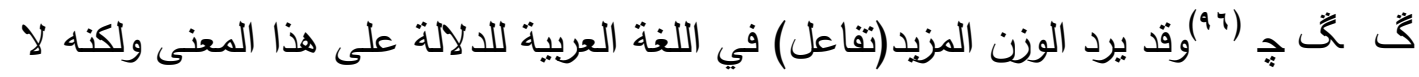
يخلو أحياناً من معنى المطاوعة نحو: باعدت عمرا فنباعد و نباعد القوم(9v) كذلك الحال في

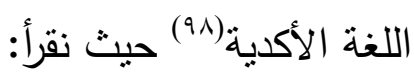

\begin{tabular}{|c|c|}
\hline اللغة الأكدية بالحرف اللاتيني & المعنى في اللغة العربية \\
\hline ina GN ni-tí-ṣí (99) & تباعدنا عن المدينة \\
\hline
\end{tabular}

\begin{tabular}{|c|c|}
\hline اللغة الأكدية بالحرف اللاتيني & المعنى في اللغة العربية \\
\hline $\begin{array}{l}\text { šumma PN i-ta-șa-am ana alikim } \\
\text { panemma dinma lublam }\end{array}$ & 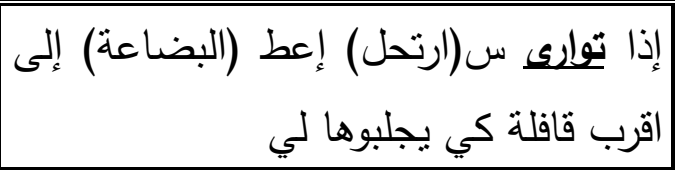 \\
\hline
\end{tabular}




\begin{tabular}{|c|c|}
\hline اللغة الأكدية بالحرف اللاتيني & المعنى في اللغة العربية \\
\hline $\begin{array}{l}\text { umma PN-ma ta-ta-lá-ak kaspī } \\
\text { dinam }^{(101)}\end{array}$ & تتباعد(ترتحل) س اعطني الفضة قبل ان \\
\hline
\end{tabular}

\begin{tabular}{|c|c|}
\hline اللغة الأكدية بالحرف اللاتيني & المعنى في اللغة العربية \\
\hline $\begin{array}{l}\text { anniam ul iddinu-ma ina bītim } \\
\text { i-te-lu-ú }\end{array}$ & بصادر البيت ليدفوا الثرط الجزائي(الضمان) \\
\hline
\end{tabular}

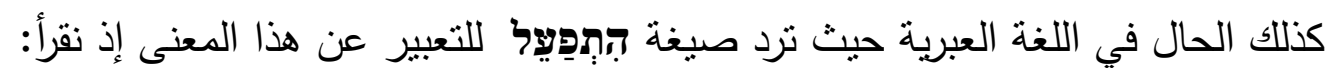

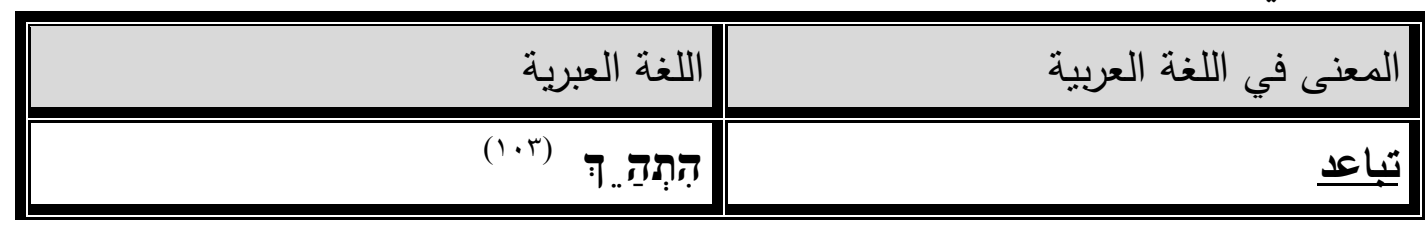

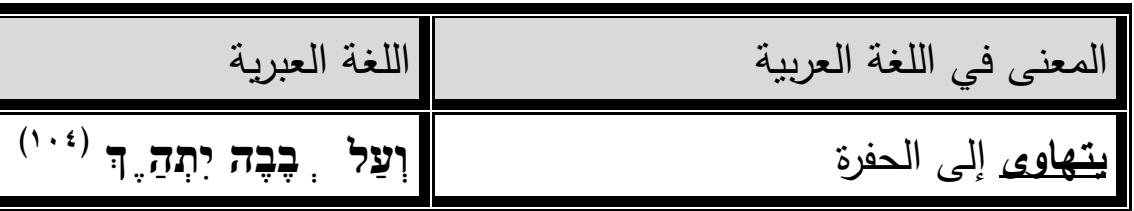

\begin{tabular}{|c|c|}
\hline اللغة العبرية & المعنى في اللغة العربية \\
\hline 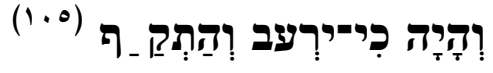 & يتيهـون في الارض مكتثبين \\
\hline
\end{tabular}

$$
\text { 4-الاتخاذ: }
$$

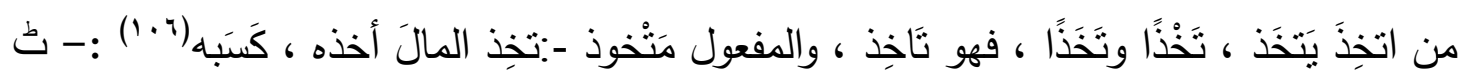

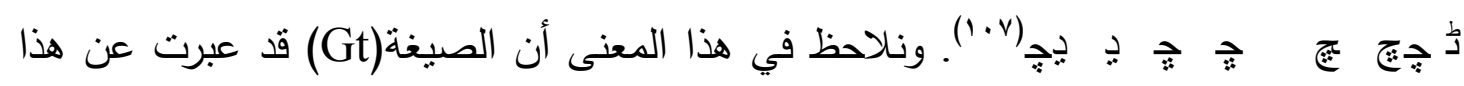

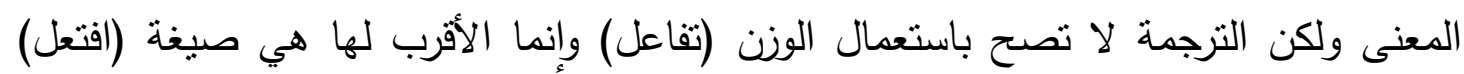
وهذا مما ذكرناه في بداية البحث إذ تتتوع الترجمة بحسب المقام بين وزن (افتعل) و (تفاعل)

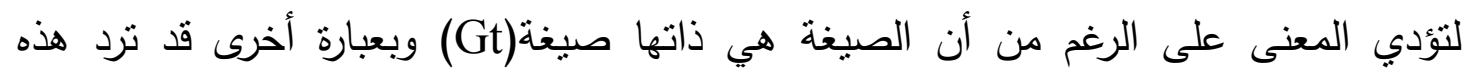

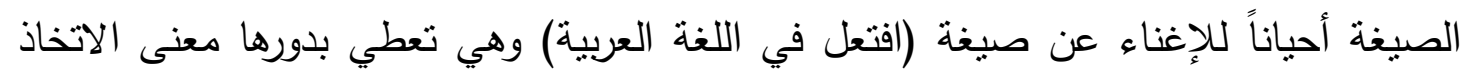
والسبطرة والامتلاك نحو : 


\begin{tabular}{|c|c|}
\hline اللغة الأكدية بالحرف اللاتيني & المعنى في اللغة العربية \\
\hline $\begin{array}{l}\text { A.Š̀̀ } \\
q u^{(108)}\end{array} \quad \ldots$ kūm dame ib-ta-at- & من امتلكوا الحقل بدلا من الدم (والنار (أي بدلاً \\
\hline
\end{tabular}

\begin{tabular}{|c|c|}
\hline اللغة الأكدية بالحرف اللاتيني & المعنى في اللغة العربية \\
\hline $\begin{array}{l}3 \text { ŠU-SI mušēṣi hurāsi ib-ta-at- } \\
q u^{(109)}\end{array}$ & 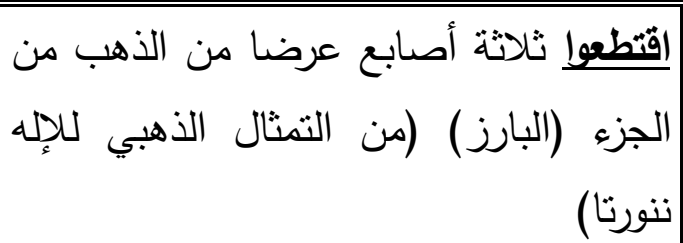 \\
\hline
\end{tabular}

\begin{tabular}{|r||r|}
\hline اللغة الأكدية بالحرف اللاتيني & المعنى في اللغة العربية \\
\hline \hline urqīt șērim ib-ta-ni(110) & التبنى الحدائق (في البلاد المفتوحة) \\
\hline
\end{tabular}

أي إتخذ حدائق

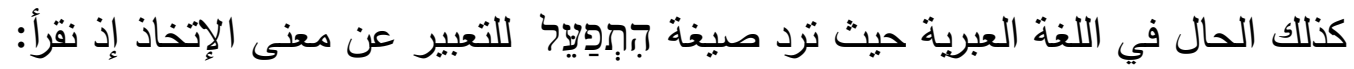

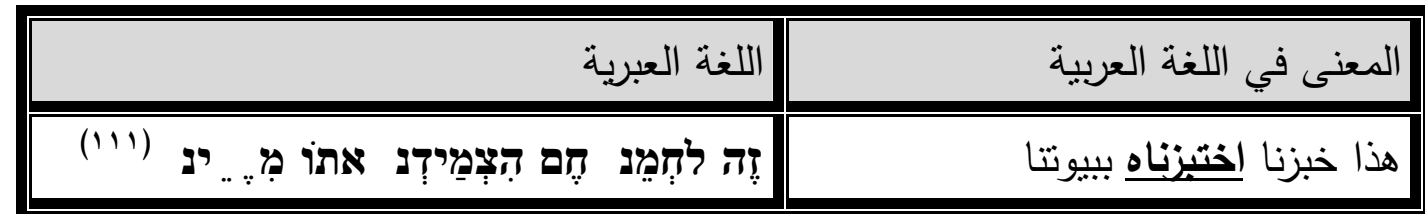

$$
\text { V الاغناء عن الثلاثي: }
$$

أي أن الصبغة المزيدة تعبر عن معنى الثلاثي المجرد(فَعَلَ) نحو قولنا في العربية: نونيث أي ونيت كذلك الحال في اللغة الأكدية فقد نرد الصيغة المزيدة(Gt) لتؤدي معنى الصيغة الأساسية وهي بذلك قليلة الورود ومقتصرة على النصوص الأدبية في الغالب ومع ذلك أمكننا تعيين بعض الثواهد:

\begin{tabular}{|c|c|}
\hline اللغة الأكدية بالحرف اللاتيني & المعنى في اللغة العربية \\
\hline $\begin{array}{l}\text { Etana pāšu ipušamma ana } \\
\text { erimma is-sà-qá-ar-šu }\end{array}$ & فتح ايتانا فاه وتكلٍ مع النسر \\
\hline
\end{tabular}

\begin{tabular}{|c|c|}
\hline اللغة الأكدية بالحرف اللاتيني & المعنى في اللغة العربية \\
\hline abatu u banû qibi li-ik-tu-nu ${ }^{(113)}$ & أعط أمراً بالتهديم ثم البناء ولتنز هذه \\
\hline
\end{tabular}




\begin{tabular}{|r||r|}
\hline المعنى في اللغة العربية الأكدية بالحرف اللاتيني & وتغادر إلى بيت ابيها \\
\hline \hline ana bit abiša it-ta-al-la-ak & اللغية \\
\hline
\end{tabular}

\begin{tabular}{|ll||l|}
\hline & اللغة الأكدية بالحرف اللاتيني \\
\hline \hline lemnēti & e tatamme damiqta ti-is- & (معنى في اللغة العربية \\
qar (115)
\end{tabular}

\begin{tabular}{|c|c|}
\hline اللغة الأكدية بالحرف اللاتيني & المعنى في اللغة العربية \\
\hline $\begin{array}{l}\text { inaana GIŠ.HI.A kalušu ip-ta-ra- } \\
\operatorname{ahg}^{(116)}\end{array}$ & والآن ازهرت كل الاشجار \\
\hline
\end{tabular}

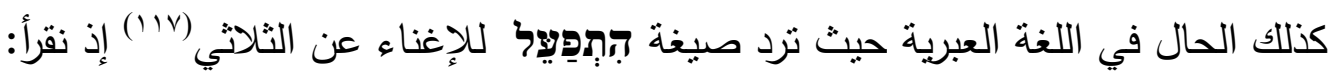

\begin{tabular}{|c|c|}
\hline اللغة العبرية & المعنى في اللغة العربية \\
\hline - 11$)_{2}$ & خلع (ثيابه) \\
\hline
\end{tabular}

\begin{tabular}{|c|c|}
\hline اللغة العبرية & المعنى في اللغة العربية \\
\hline הִתְּנּ.. א (119) & تتبأ(بنبوءة) \\
\hline
\end{tabular}

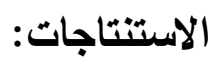

توصل البحث إلى مجموعة من الاستتاجات منها ما هو مدون في متته ومنها مما سوف نذكره بالإجمال:

ا- لم تكن اللغة الأكدية قاصرة عن أداء المعاني حيث عبرت عنها باستعمال الصيخ المزبدة،

$$
\text { - ولاسيما صبغة (Gt) }
$$

ץ- أكدت الدراسة على مجموعة من القواعد الخاصة التي تساعد الدارس في هذا المجال على التفريق بين صيغة التام وصيغة (Gt) الماضية. ب- تتشابه صيغة iptaras في اللغة الأكدية مع صيغة (افتعل) في اللغة العربية تشابها صونياً ،إلا أن الصيغة الأقرب دلالياً هي صيغة (تفاعل) وأحياناً يمكن أن تتنوع الترجمة بين استعمال فئه فئه صيغة(افتعل) وصيغة (تفاعل) فضلاً عن صيغة(فعل) وذلك كله يحدد بحسب المعنى والسياق. 


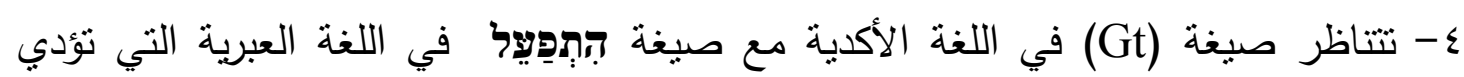
المعنى ذاته.

ه- من المرجح أن يكون الأكديون قد استعملوا همزة الوصل للتعبير عن صيغة (Gt) للغائب المذكر والمؤنث إفراداً وجمعاً، إلا أنها استعاضت عنها بالكسرة للدلالة عليها ولعل هذا يكون أحد أوجه كتابة الهزة في اللغة الأكدية ،وعلى ذلك هي تتاظر صيغة (افتعل) في اللغة العربية صوتياً. צ-هنالك بعض التغيرات الصوتية التي قد نطرأ على صيغة (Gt) حيث تتوزع هذه التغيرات على وجهين ،الوجه الأول :القلب المكاني وهو أن يتغير موقع تاء الزيادة في الجملة مثل tisbat و tisqar حيث ان اللفظ الأساس لهما sitqar و و sitbat الوجه الثاني: الإبدال وهو أن يدغم حرف الزيادة التاء مع حرف آخر مشنابه لله ليولد حرف جديد يجمع الصوتين.

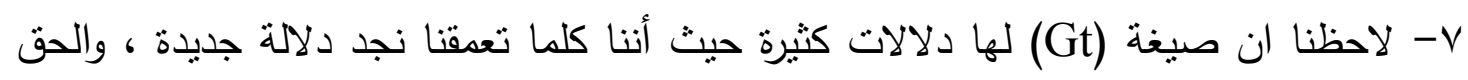
يقال أن هذه الصبغة حبلى بالدلالات ، وقد آن لهذا المولود أن يرى النور وذلك في ضوء المنهج التحليلي والوصفي لبيان عناصر هذه الدلالات، كما أن منهج مقارن أفادنا بالعديد من الظواهر اللغوية الغامضة التي كانت تكتتف هذه الصيغة. 1- تتصرف صيغة (Gt) الى الأزمنة جميعها الماضي والمضارع والأمر، إلا أننا نرى أن الغرض الأول من وضعها هو لتأدية معانٍ جديدة قصرت الصيغة الأساس عن حملها. 9- تبين من الدراسة أن صيغة (Gt) قد أدت معاني عدة كالمشاركة والمطاوعة والتظاهر والمباعدة والتتابع والاتخاذ كما أنها أغنت عن الثناثي في بعض الأماكن، ألا أننا نرى ان غالبية المعاني لا تخلو من معنى المطاوعة . • 1- لوحِظ من الدراسة أن صيغة التام iptaras هي أقرب للأصل من اللغة العاربة الأم. وهي صيغة اختصت بها اللغة الأكدية دون أخواتها من العائلة ذاتها، ونرى بأنها أبلغ من اللغتين العربية والعبرية لأنها عنت الزمن المنشود من دون الرجوع إلى القرائن اللفظية والمعنوية. وربما

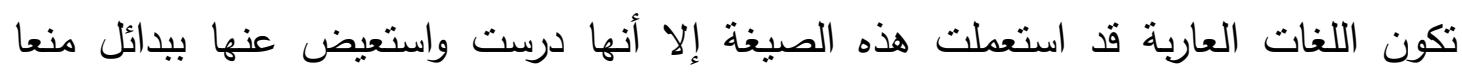
للتشابه الذي قد يحصل بينها وبين صيغ الزيادة، وهذا مما لاحظناه في اللغة الأكدية التي مالت إلتهات في فنرات متأخرة إلى استعمال القرينة الظرفية ahames مع الفعل الثلاثي لأداء معنى المشاركة الذي هو من خصوصيات الصيغة(Gt) • والله الموفق 


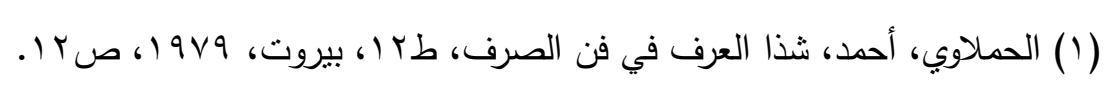

(2) AKKH, p. 1; GAKK, p. 252.

(3) GHG, p. 510.

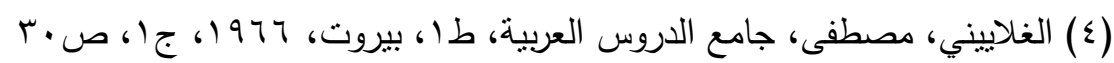

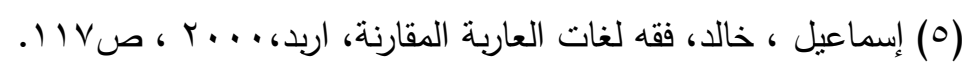

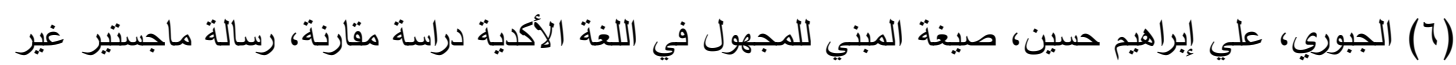

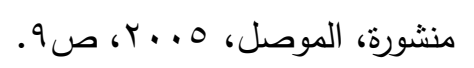

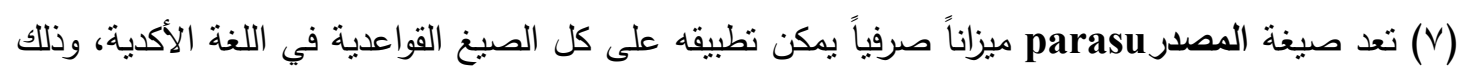

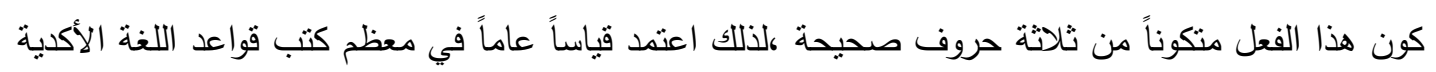

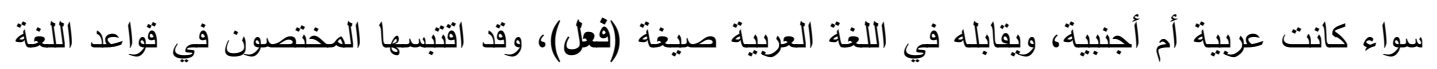

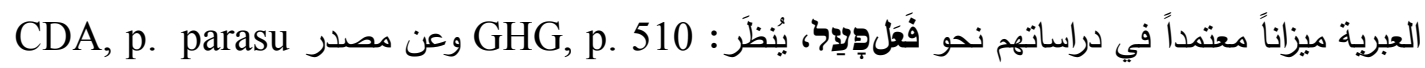

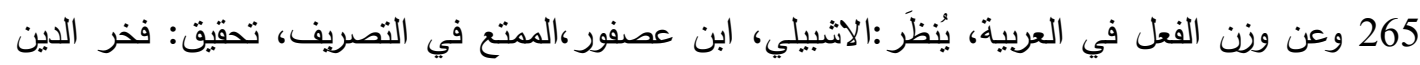

(9) GHG, p. 149.

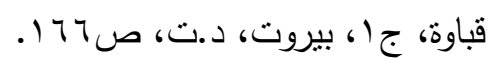

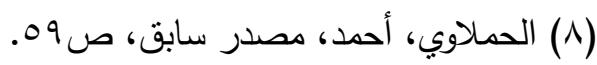

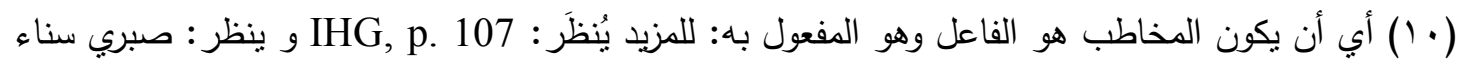

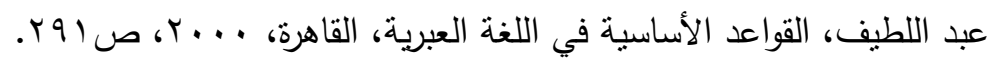

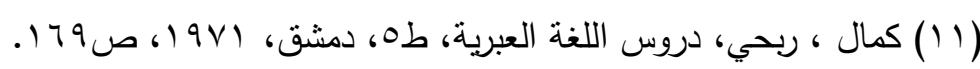

(12) IAKK,p.90;GAG, p. 124e.

(13) GAG, p. 124e.

(14) IHG, p. 106.

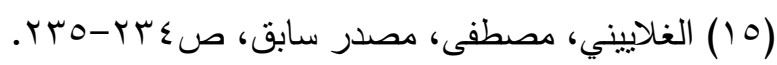

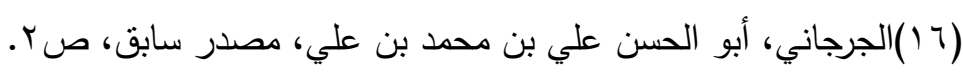

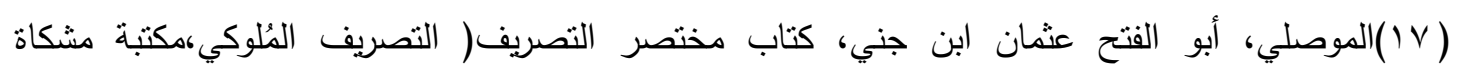

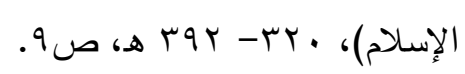

(1) (1) ظهرت نسميات عدة للالالة على هذه المجموعة من اللغات، فقد استعمل الباحث اليهودي النمساوي

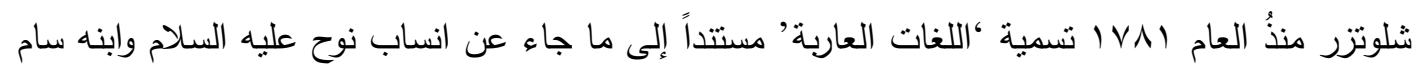

$$
\text { (سفر النكوين). }
$$

يُنظر:SLOCG, P, 21; ICG, P.3 ؛ سليمان، عامر، اللغة الأكدية (البابلية - الآثورية)، طبعة منقحة

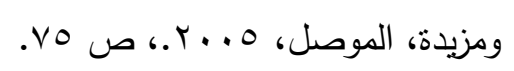

إلا أن عدم دقة هذهِ التسمية من جميع الجوانب اللغوية والثاريخية والجغرافية واكتسابها معانٍ سياسية جديدة

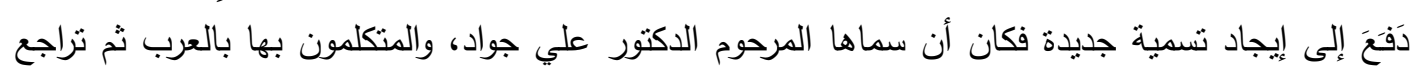

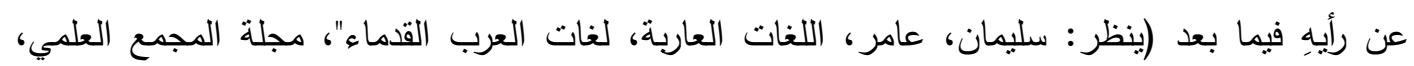

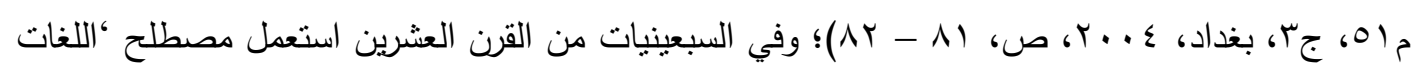




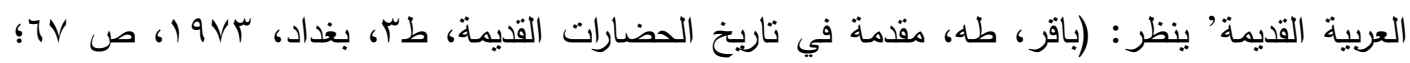

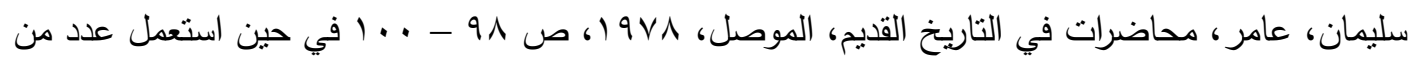
الباحثين العراقيين تسمية جديدة أخرى هي 'اللغات الجزرية، (ينظر : الأحمد، سامي سعيد، المدخل إلى

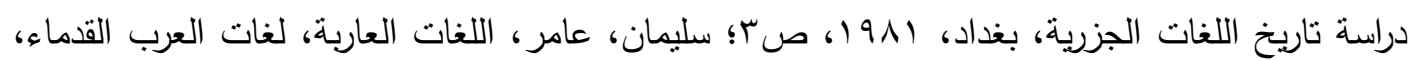

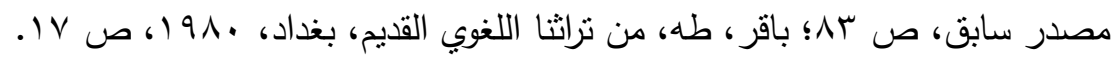

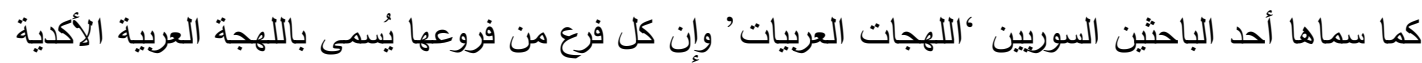
أو اللهجة العربية الآرامية وهكذا (يُنظر : قبيسي، محمد بهجت، ملامح في فقه اللهجات العربيات من الأكادية

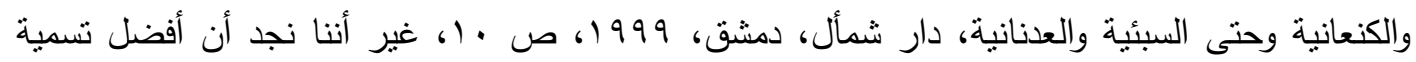

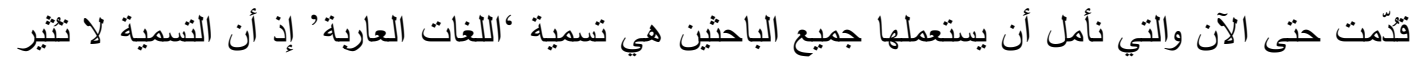
أي التباس أو غموض (يُنظر : تفصيل ذلك، سليمان، عامر، اللغات العاربة، لغات العرب القدماء، مصدر

(19) IAKK,p.31. سابق، ص Vo - V)

(20) GAKK,p.390.

(21) GAKK,p.155.

(22) IAKK,p.40.

(YT) يونس، أمين عبد النافع أمين، أزمنة الفعل في اللغة الأكدية، دراسة مقارنة ، أطروحة دكتوراه غير منشورة، (24) AKKG, p.145; MSL, 5.

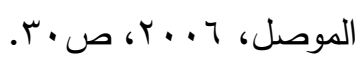

(Yo) الجبوري ، علي إبراهيم حسين ، المصدر السابق ، صـ ا ؛.188GS, p. (26)GAKK , P . 390 .

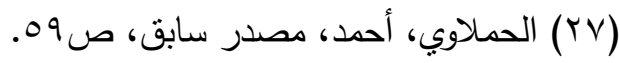

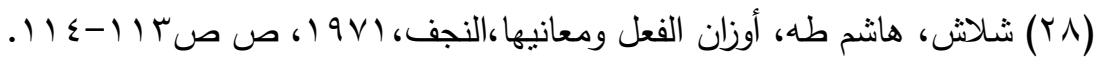
(29) GHG, p. 149.

(ץ) استعملت اللغة الأكدية الصيغة ذاتها للتعبير عن المذكر والمؤنث المفرد الغائب وذلك في عموم صيغ التصريف للأفعال.

(اسبتعملت اللغة العبرية الصيغة ذاتها للتعبير عن المذكر والمؤنث الجمع الغائب وذلك في عموم صيخ (32)GAKK , P . 390 . التصريف للأفعال: للمزيد من التقصيل ينظر :IHG,p.264

(34)GHG, p. 149. (rr) الحملاوي، مصدر سابق، ص99. (م) استعطلت اللغة العبرية الصيغة ذاتها للتعبير عن المذكر والمؤنث الجمع الغائب وذلك في عموم صيغ التصريف للأفعال: للمزيد من التفصيل ينظر :IHG,p.264 (דب) إن الأقرب والأكثر تطابقاً في اللغة العربية من الناحية التصريفية مع صيغة الفعل التام في اللغة الأكدية بغض النظر عن الأداء الوظيفي للصيغة هي صيغة (افتعل) ، وهي صيغة ثلاثية مزيدة بهمزة الوصل في

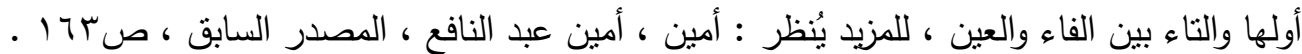

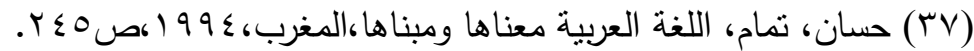

(38)RHT, p.47. 


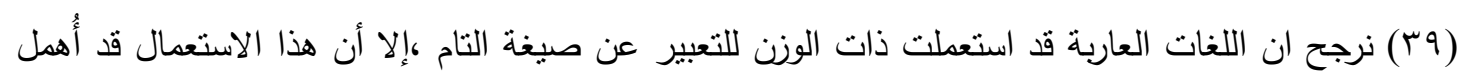

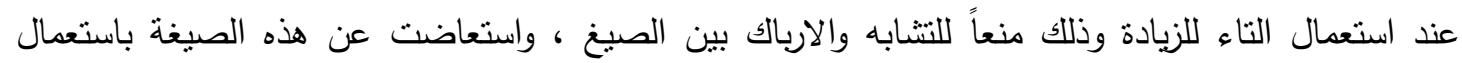
القرائن اللفظية منلما استعاضت اللغة الأكدية عن صيغة الزيادة (Gt) في عصور متأخرة باستعمال القرينة

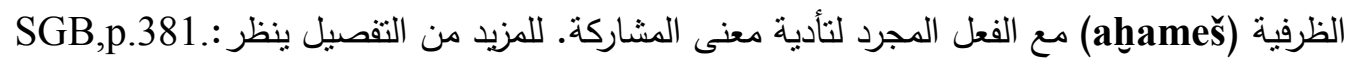

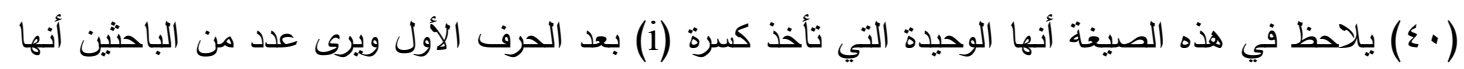

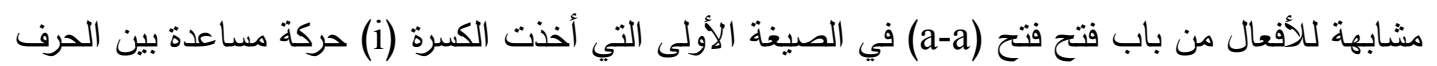
الأول والثاني يُنظرَ: , Gelb, L, "Notes on von soden's Grammar of Akkadian" ( .1955,pp,93-111., p. 110

(41)GAKK, p. 142, GAG, p. 105.

(42)Cook,J.A., Biblical Hebrew a Student Grammar, Welmore, 2009;GHG, p. 124. (43)SLOCG, p.334.

(44)IAKK, p. 28.

(45)IHG,p.58.

(؟7) محمد، مصطفى محسن، الاسلوب الطلبي في اللغة الأكدية دراسة مقارنة مع اللغة العبرية، رسالة

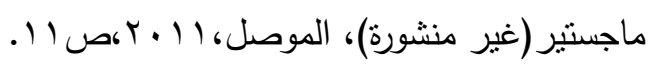

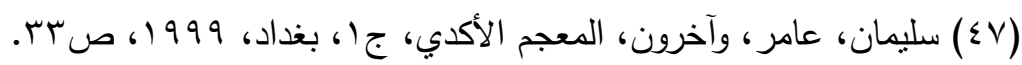

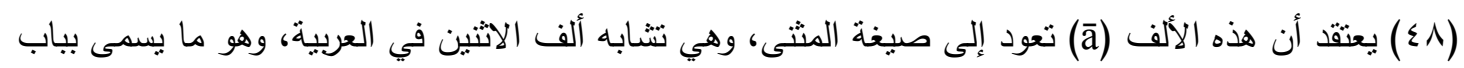

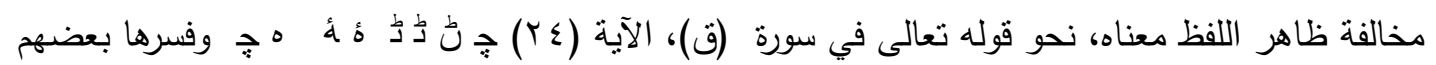

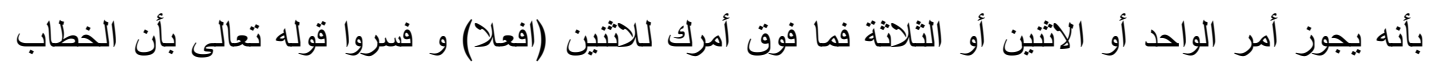
كان موجهاً إلى خزنة جهنم وزبانيتها أي(للجماعة)، للمزيد عن هذا الموضوع يُنظَر :السيوطي، جلال الدئ الدين، (49)GHG, p.124; IHG, p. 85.

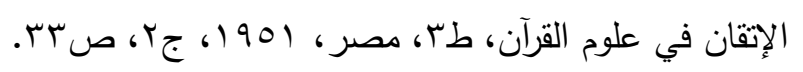

(0) בלאו יהו ע ، תורת ההגה והצורות ، הוצאת הקיבוץ המאוחד ،1985. עמ'118. (51)GHG, p. 125.

(52)GAKK, p. 611..

(53)FAOS, Vol. 14/2, p.97.

(54)GAG, p. 124e.

(00) الجوهري، أبو نصر إسماعيل حماد، الصحاح، تحقيق: أحدد عبد الغفور عطار، دار الكتاب العربي،

(56)GAG,p.150.

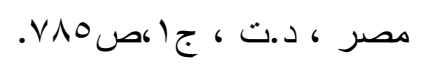

(57)CAD, Š2,p.37.

(58)CAD,M2,p.81.

(59)CAD, Š1,p.368.

(60)CAD,S, p.34.

(61)CAD,Šs3,p.143.

(62)CAD,M1,p.82.

(63)CAD,N2,p.127.

(64)CAD,N2,p.127.

(65)CAD,N2,p.127. 


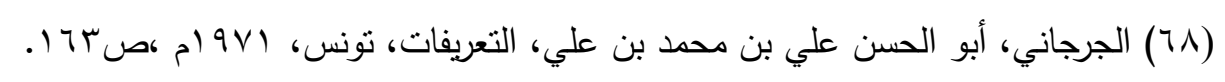

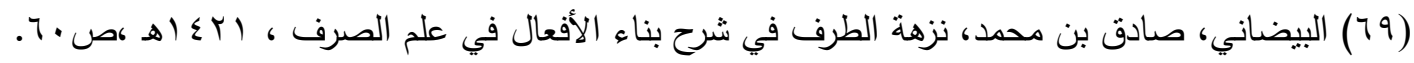
(70)GAKK,p.393;IAKK,p.39.

(71)CAD,P,p.248.

(72)CAD,N1,p.4.

(73)CAD,A1,p.23.

(74)CAD,N1,p.4.

(75)CAD,A1,p.106.

(76)IHG,p.107.

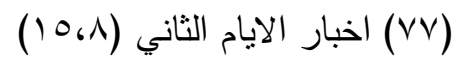

(78)IHG,p.107.

(V9)(ابن منظور، أبو الفضل جمال الدين محمد بن مكرم، لسان العرب الدحيط، كتاب الدال، بيروت،

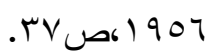

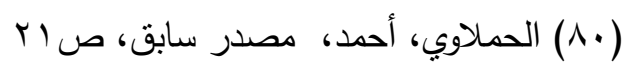

(81)CAD,A1,p.256.

(82)CAD,R,p.88.

(83)CAD,R,p.239.

(84)PGCH,p.118.

(85)GHG,p.150.

(T)(ابن منظور ، أبو الفضل جمال الدين محمد بن مكرم، مصدر سابق، كتاب الظاء،ص آب.

(88)CAD, ̌̌s 1,p.491.

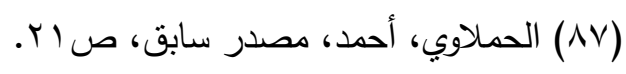

(89)CAD,E,p.124.

(90)CAD,P,p.141.

(91)CAD, S2,p.37.

(92)CAD,P,p.210.

(93)GHG,p.150.

(94)GHG,p.150; IHG,p.107.

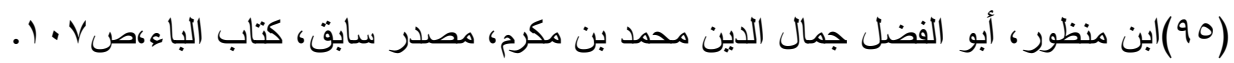
(97) سبأ آية 19 (90)

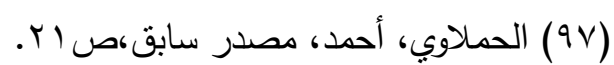

(98)GAG,p.150;GAKK,p.393.

(99)CAD,A2,p.358.

(100)CAD,A2,p.358.

(101)CAD,A1,p.322.

(102)CAD,E,p.124.

(103)IHG,p.107.

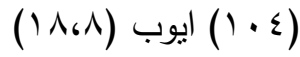

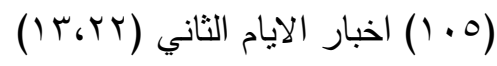

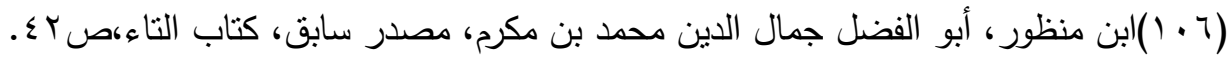

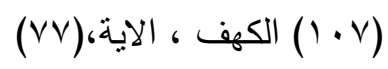


(108)CAD,B,p.162.

(109)CAD,B,p.162.

(110)CAD,B,p.84.

(112)CAD,Z,p.21.

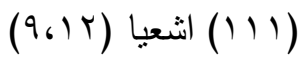

(113)CAD,K,p.162.

(114)CH, 145:5.

(115)CAD,Z,p.21.

(116)CAD,P,p.145.

(117)GHG,p.149.

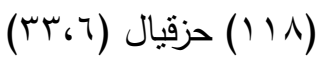

قائمة المصادر

أولاً: المصادر العربية.

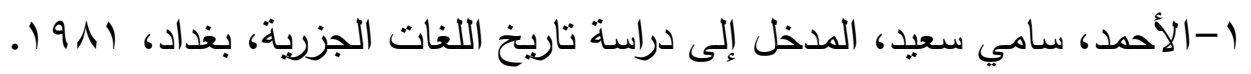

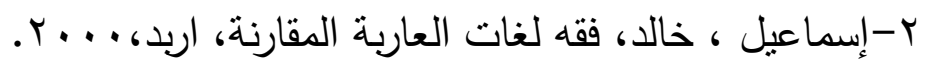

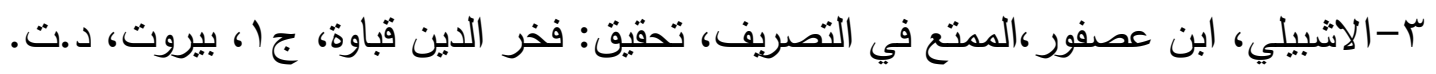

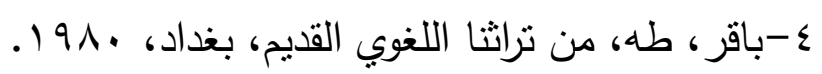

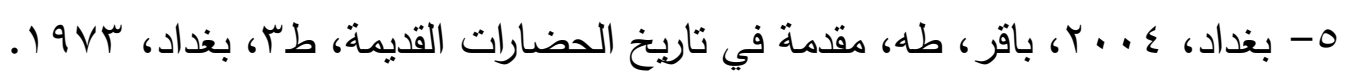

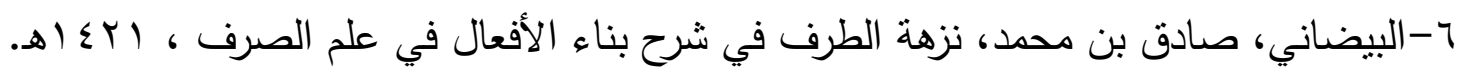

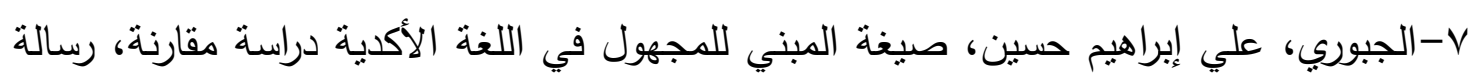

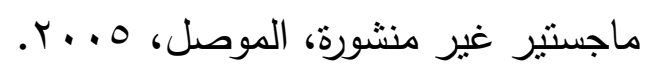

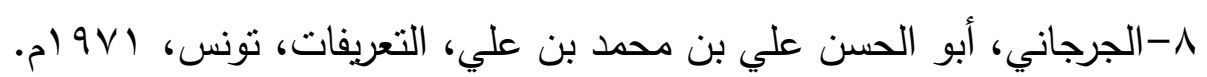

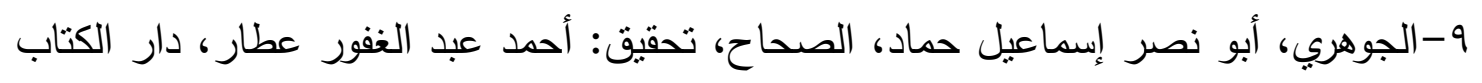

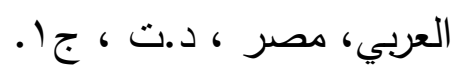

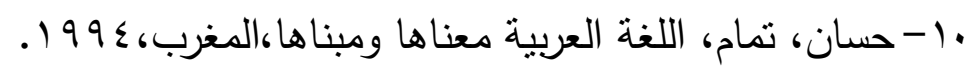

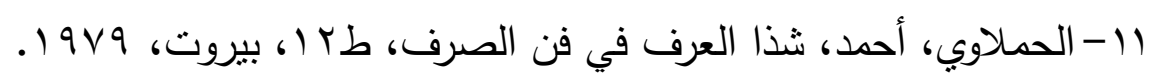

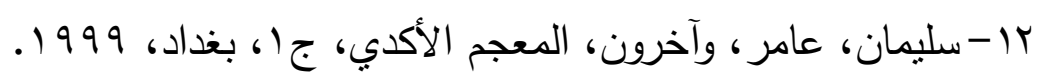

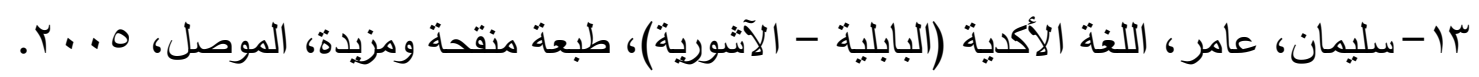

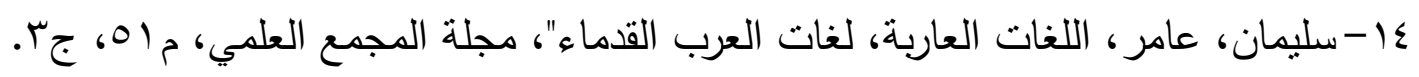

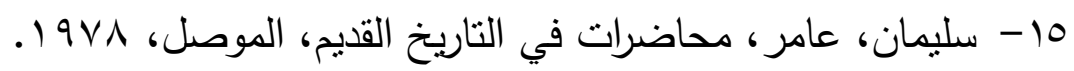

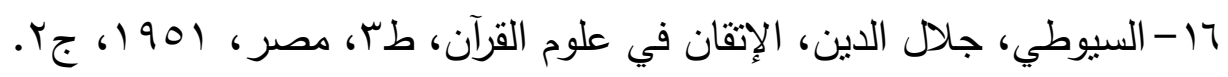

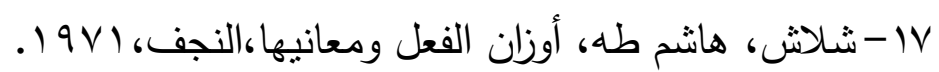


11 - صبري سناء عبد اللطيف، القواعد الأساسية في اللغة العبرية، القاهرة، ... . .

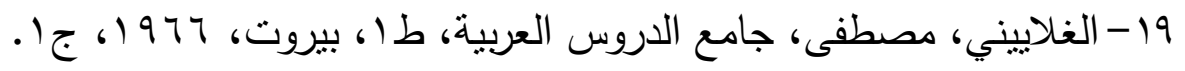

• ب-قبيسي، محمد بهجت، ملامح في فقه اللهجات العربيات من الأكادية والكنعانية وحتى السبئية.

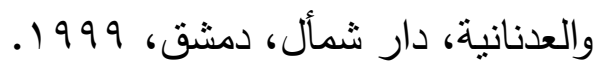

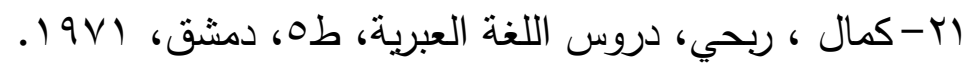

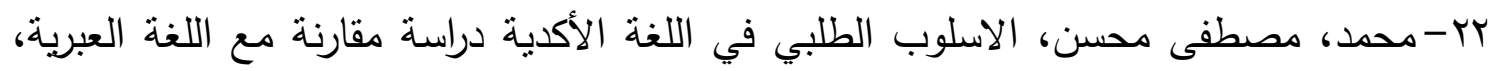

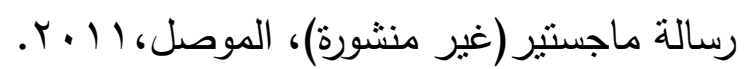

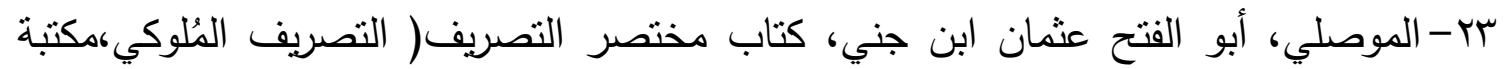

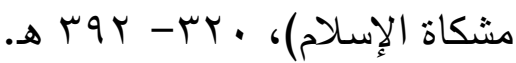

ع ب- يونس، أمين عبد النافع أمين، أزمنة الفعل في اللغة الأكدية، دراسة مقارنة ، أطروحة دكتوراه

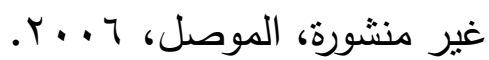

ثانياً: المصادر العبرية ו- בלאו יהו ע ، תורת ההגה והצורות ، הוצאת הקיבוץ המאוחד ،1985.

ثالثاً: المصادر الاجنبية

1. Bennett,P.R, Comparative Semitic Linguistics, Elsenbrauns,1998.

\section{CSL}

2. Black,J,And Others. A Concise Dictionary of Akkadian,Wiesbaden, 2000. $\underline{\boldsymbol{C D} \boldsymbol{A}}$

3. Buccellati, G, A Structural Grammar of Babylonian, Wiesbaden. $\underline{\boldsymbol{S G B}}$

4. Caldwell, S.J., And Others, An Akkadian Grammar, A translation of Riemschneider's Lehrbuch des Akkadischen, 5nd Ed,USA, 1978. $\underline{A A K K G}$

5. Caplice, R., Introduction to Akkadian, Rome, 1980. $\underline{\boldsymbol{I A K K}}$

6. Codex of Hammurabi. $\boldsymbol{C H}$

7. Cook,J.A., Biblical Hebrew a Student Grammar, Welmore, 2009.

8. Cowley, A. E, Gesenius' Hebrew Grammar, Oxford, 1910. $\underline{\boldsymbol{G H} G}$

9. Davidson ,A .B.,An Introductory Hebrew Grammar ,25th ed ,Holland ,1962. $\underline{\boldsymbol{H H G}}$

10.Driver, G.R., and Miles, J.C., The Babylonian Laws, Codex of Hammurabi. $\boldsymbol{C H}$, Vol, 2, Oxford, 1955.

11.Frank, R.,Blake, Resurvey of Hebrew Tenses, Roma,1968. $\underline{\boldsymbol{R H T}}$ 
12. Gelb, L, "Notes on von soden's Grammar of Akkadian" ( $\underline{\boldsymbol{B i} \boldsymbol{O} \boldsymbol{r}}), 12$, 1955.

13. Gronberg ,B.R.M.,Syntax ,Morphologie und Der Jung Babylonischen "Hymnischen" Leteratur ,Wiesbaden ,1987, ( $\underline{\text { FAOS }}), 14 / 2$.

14.Huehnergard, J, A, Grammar of Akkadian, Atlanta, 1997. $\underline{\boldsymbol{G A K K}}$

15.Landsberger,B.,Materialien Zum Sumerischen Lexikon,Roma,1937. $\underline{M S L}$

16.Lapin, L, A. The Akkadian Language, Moscow, 1973. AKKL

17.Lipinski, E, Semitic Languages Outline of Comparative Grammar, 2nd Ed, Leuven, 2001. SLOCG

18. Miller ,B. D ., and Shipp ,R. M ., An Akkadian Handbook ,Indiana ,1996. $\underline{\text { AKKH}}$

19. O'leaiy, DE Lacy, Comparative Grammar of the Semitic Languages, Amsterdam, 1969. $\underline{\text { CGSL }}$

20. The Assyrian Dictionary of the oriental institute of the University of Chicago, 1956. $\underline{\boldsymbol{C A D}}$

21.Ungnad ,A ., Akkadian Grammar ,5th ,ed., Translation by Harry A.Hoffner .JR .,Chicago ,1992. $\underline{\boldsymbol{A K K} \boldsymbol{G}}$

22.Von Soden, W., Grundriss der Akkadischen Grammatik, Roma,1952. GAG

23. Weingreen, J. A, Practical Grammar for Classical Hebrew, Oxford, 1959. $\underline{\boldsymbol{P G C H}}$

24.Wright, W, Lectures on the Comparative Grammar of the Semitic Languages, Amsterdam, 1966. LCGSL 

Contents

\begin{tabular}{|c|c|c|}
\hline Page & Research Name & Subject \\
\hline 1 & Prof. Khalid Salim Ismael & Preface \\
\hline $3-82$ & Prof. Dr. Wathiq Al-Salihi & Palm Trees in the Arts of Mesopotamia \\
\hline $83-94$ & $\begin{array}{l}\text { Haneen Abdulghani Jasim } \\
\text { Prof. Khalid Salim Ismael }\end{array}$ & $\begin{array}{c}\text { Lights on the Royal Edicts from Old } \\
\text { Babylonian Period } \\
\text { Analytical Study }\end{array}$ \\
\hline $95-132$ & Prof. Dr. Amir Abdullah al-Jumaily & $\begin{array}{l}\text { Some of Caravan Route Cities and } \\
\text { Road Stations Throughout Ancient } \\
\text { And Islamic History in the Light of } \\
\text { Cuneiform Texts and Arabic Sources }\end{array}$ \\
\hline $133-160$ & $\begin{array}{l}\text { Asst.Pro.Dr.Fatimaa Abbas Salman } \\
\text { Pro.Dr. Saad Salman Fahed }\end{array}$ & $\begin{array}{l}\text { Tamarisk Tree in Light of Cuneiform } \\
\text { Writings A joint Submitted by } \\
\text { Research }\end{array}$ \\
\hline $161-186$ & $\begin{array}{l}\text { Assist-Prof.Dr. Noman Jumaah } \\
\text { Ibrahim }\end{array}$ & $\begin{array}{l}\text { The Achievements of Prehistoric } \\
\text { Human in Iraqi Kurdistan and } \\
\text { Manifestations of his Civilization } \\
\text { Until the End of the Upper Paleolithic }\end{array}$ \\
\hline $187-204$ & $\begin{array}{c}\text { Qassim Omar Allawi } \\
\text { Dr. Sufyan Yasen Ibrahim }\end{array}$ & Urban activities in Indian ports \\
\hline 205-221 & Dr. Hani Abdulgani Abdullah & $\begin{array}{c}\text { Appearances of Cleanliness in the } \\
\text { Hittite Society }\end{array}$ \\
\hline $223-250$ & Dr. Mustafa Mohsen Muhammad & $\begin{array}{c}\text { The (Gt) Stem in the Akkadian } \\
\text { Language a Semantic and } \\
\text { Morphological Study Comparing } \\
\text { Between Hebrew and Arabic } \\
\text { Languages }\end{array}$ \\
\hline 251-269 & $\begin{array}{c}\text { Asst.Lect. Abdulmakram } \\
\text { Mahmoud Mohammed Alezzi }\end{array}$ & $\begin{array}{l}\text { A Study of The Sumerian Term } \text { NIG }_{2^{-}} \\
\text {KAS }_{7 . .} \text { AK (Balanced Account)In The } \\
\text { Texts of The Third Millennium B.C }\end{array}$ \\
\hline $271-287$ & Lecturer. Hasan M. Hammoodi & $\begin{array}{c}\text { The Sickle Industry Developed In } \\
\text { Ancient Iraq During The Mesolithic To } \\
\text { The End Of Chalcolithic }\end{array}$ \\
\hline
\end{tabular}


12- The original research papers submitted to the magazine are not returned to their owners, whether published or not.

13- Tables and figures are numbered in a row according to their appearance in the research, provided with titles, submitted with separate papers, blueprints are submitted in black ink and images to be in high resolution.

14- The marginal numbers are written in parentheses and are presented in series at the end of the research.

15- The full source name is indicated in the margin, with the abbreviated source in parentheses at the end of the margin.

16- The researcher is responsible for correcting the linguistic and typographical errors in his research.

17- The magazine operates according to self-funding. Therefore, the researcher bears the publication fees of $(100,000)$ one hundred thousand Iraqi dinars.

18- Each researcher shall be provided with one copy of his research. As for the full copy of the journal, it is requested from the magazine's secretariat and a price is determined by the Editorial Board.

19- The papers should be sent to the journal e-mail:

uom.atharalrafedain@gmail.com 


\section{Publishing rules in Athar Al-Rafedain Journal (AARJ):}

1- The journal accepts scientific research that falls in specializations:

- Ancient Archaeology and Islamic Archaeology .

- Ancient languages with their dialects and comparative studies.

- Cuneiform Inscriptions and ancient lines.

- Historical and cultural studies

- Archaeological geology.

- Archaeological survey techniques.

- Anthropological studies.

- Conservation and restoration.

2- Research papers shall be submitted to the magazine in both Arabic and English.

3- The research shall be printed on (A4) paper, word-2010 system, with double spaces between lines, Simplified Arabic font for Arabic language, Times New Roman for English language, delivered on $\mathrm{CD}$, and in two paper based copies.

4- The title of the research should be printed in the middle of the page, followed by the name of the researcher, his academic degree, his full work address, and e-mail.

5- The research should contain an abstract in Arabic and English languages, it shouldn't exceed (100) words.

6- The abstract of the research in English contains the title of the research, the name of the researcher, his academic degree, his full workplace, and his e-mail.

7- The research must include keywords related to the title of the research and its content.

8- That the research was not previously published or was submitted to obtain a degree or is derived from the intellectual property of another researcher, and the researcher must undertake this in writing when submitting it for publication.

9- The researcher is obliged to follow the correct scientific foundations in his research.

10- The researcher is obligated to amend his research terms to suit the experts 'suggestions and the method of publishing in the journal.

11- The number of research pages does not exceed (25) pages, and in case of exceeding the required number, the researcher shall pay an additional amount for each additional page. 


\author{
Arabic Language Expert \\ Dr. Maan Yahya Mohammed \\ Dep. Of Arabic Language /College of Arts / University of Mosul
}

\author{
English Language Expert \\ Assist. Lect. Ammar Ahmed Mahmood \\ Dep. Of Translation Language / College of Arts / University of Mosul
}

Design Cover

Dr. Amer Al-Jumaili 


\title{
$\underline{\text { Editorial Board }}$
}

\author{
Prof. Khalid Salim Ismael \\ Editor-in-Chief
}

\section{Assist Prof. Hassanein Haydar Abdlwahed \\ Managing Editor}

\section{Members}

Prof. Elizabeth Stone

Prof. Adeileid Otto

Prof. Walther Sallaberger

Prof. Nicolo Marchetti

Prof. Hudeeb Hayawi Abdulkareem

Prof. Jawad Matar Almosawi

Prof. Rafah Jasim Hammadi

Prof. Abel Hashim Ali

Assist Prof. Yasamin Abdulkareem Mohammed Ali

Assist Prof. Vyan Muafak Rasheed

Assist Prof. Hani Abdulghani Abdullah 



\section{Journal}

\section{Athar Al-Rafedain}

Accredited Scientific Journal

It Search's in Archaeology of Iraq and Ancient Near East

Published by College of Archaeology - University of Mosul

E-Mail: uom.atharalrafedain@gmail.com

Vol.6 / No.2

Shwal. 1442 A.H. / June. 2021 A.D. 

$\frac{3}{3}$

University of Mosul College- of Archaeology

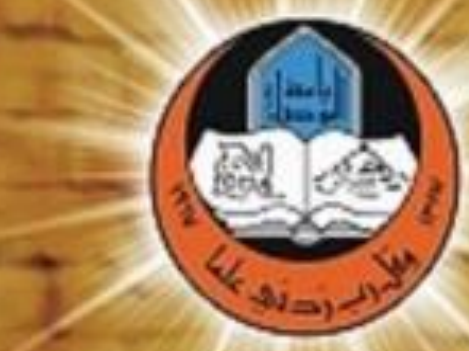

Ministry of Higher

Education and Soientific

Research

ISSN 2304-103X

|रि口प

Academx Socreithe soumals

2

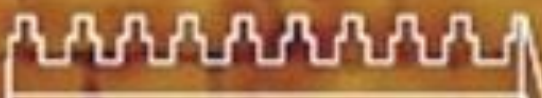

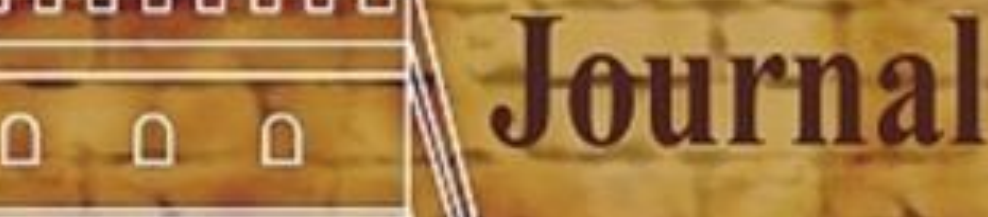

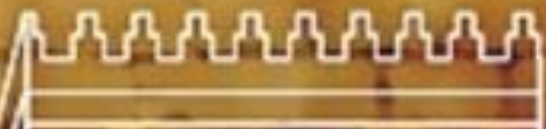

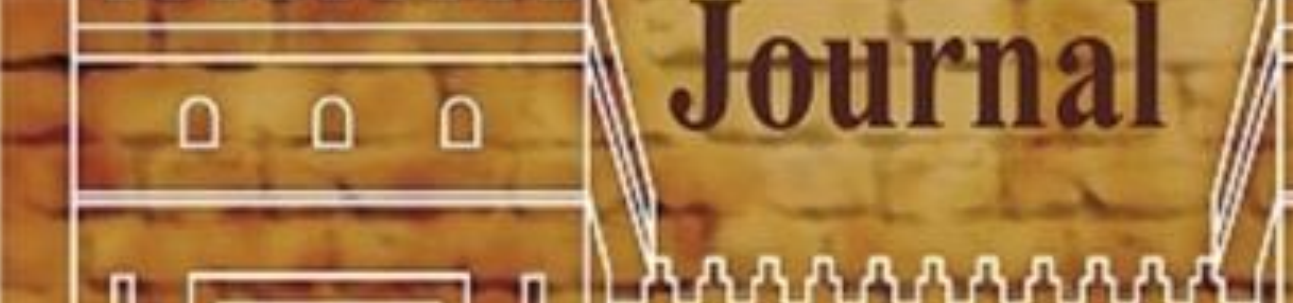

r

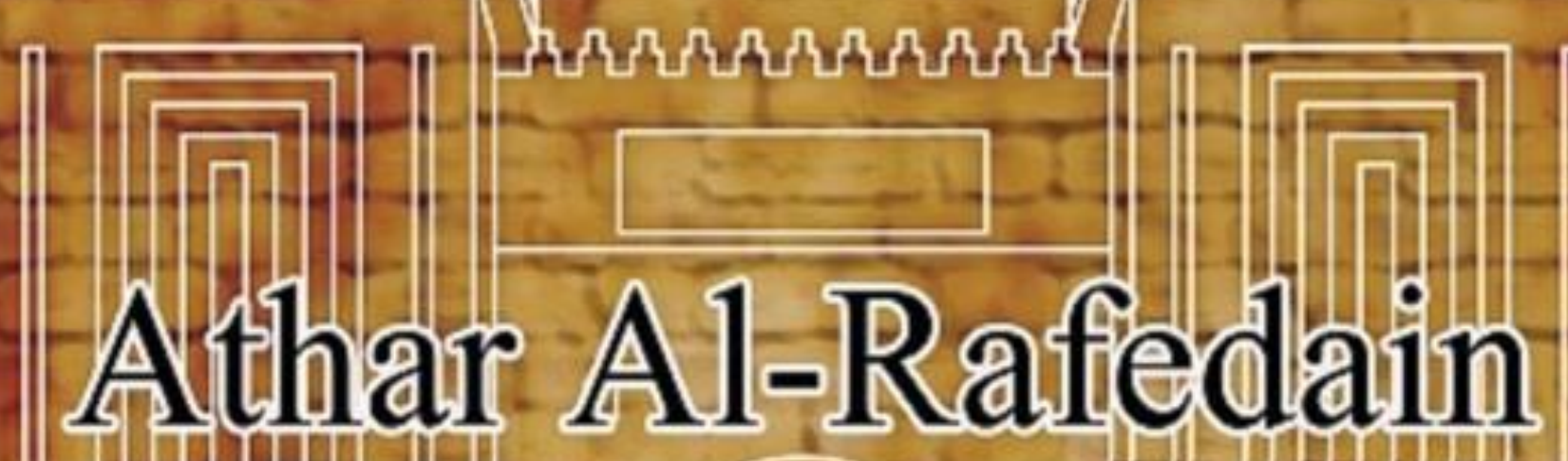

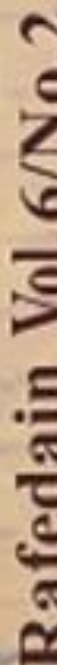

m.thin

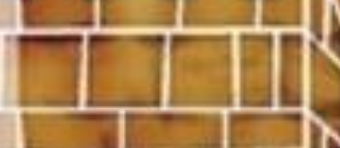

1 II

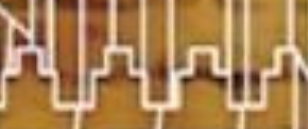
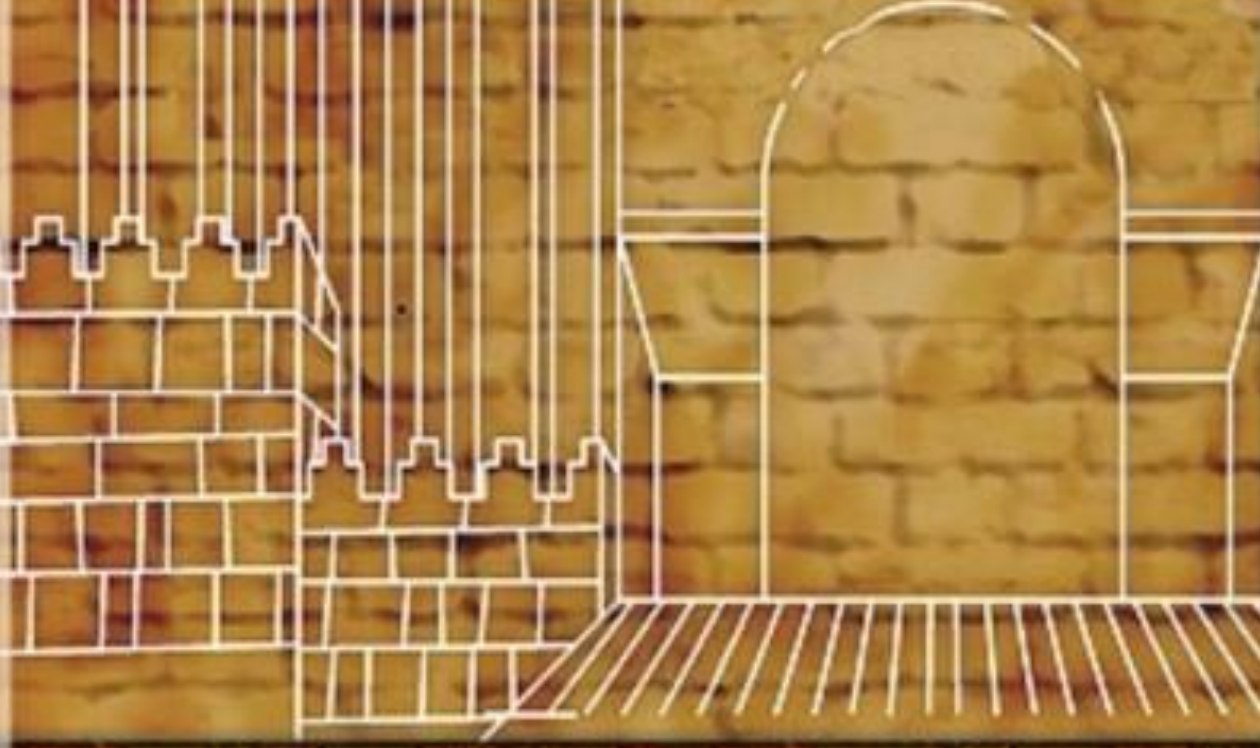

Q $-0 .-0$

$\frac{1}{2}$

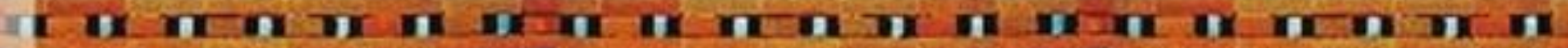

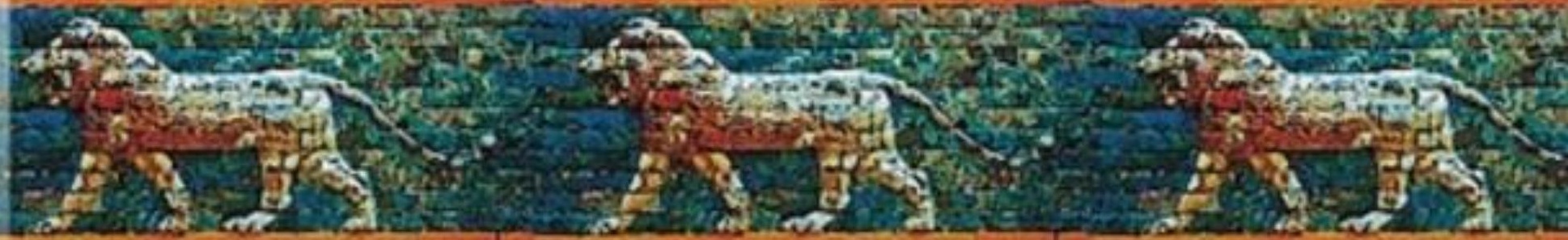

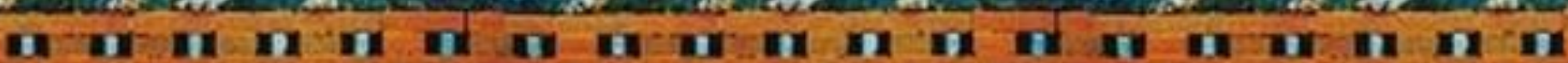

Accredited Scientific Journal It Search's in Archaeology of Iraq and Ancient Near East

Published College of Archaeology - University of Mosul / Vol.6/ No.2 / 1442 A.H. / 2021 A.D. 